\title{
DYNAMIC EVOLUTION
}

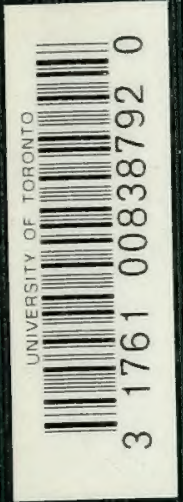

CASPER L. REDFIELD 
QH371.R35 
Digitized by the Internet Archive in 2008 with funding from Microsoft Corporation 




\title{
Dynamic Evolution
}

\author{
A Study of
}

The Causes of Evolution and Degeneracy

\author{
By
}

\section{Casper L. Redfield}

G. P. Putnam's Sons

New York and London

Tbe Iknickerbocker Dresg

I9I4 


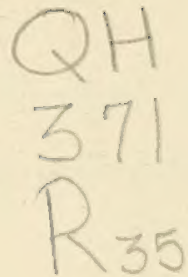

COPYRIGHT, I9I4

$\mathrm{BX}$

CASPER L. REDFIELD

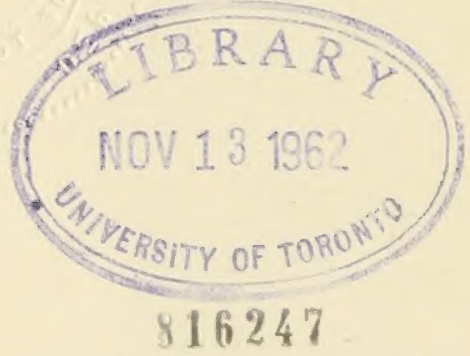

Tbe Knickerbocker Press, Acw Dork 


\section{PREFACE}

SCIENTISTS think they believe in evolu$\int$ tion, but they really believe in special creation. They have established, with a fair degree of certainty, that the animals of today are the genetic descendants of different animals of earlier ages, but their explanations of how the earlier animals became transformed into the present animals involves nothing but special creation.

Our present animals may be descended, through successive stages, from unicellular organisms, but such a thing as human intelligence was not derived from man's ancestors because man's ancestors did not possess human intelligence. Somewhere and at some time there have been created those things which characterize modern animals. The Mosaic account gives this work of creation as being the direct act of a Creator in the 
Garden of Eden. Removing the act of creation from the Garden of Eden to the germ, and dividing it into small parts so that it will extend over long lines of generations, does not change the essential character of the creation involved.

To say that human intelligence and those other qualities peculiar to modern animals are the product of growth, is to hide behind words. If one generation has less of these qualities than the preceding generation, that less may be due to something lost or omitted; but if it has more than preceding generations had, that more means that something has been created which did not previously exist. Animals grow by assimilating food, but no degree of feeding will produce a poet, a statesman, or an inventor. There is a clear distinction between increasing the quantity of a given material in a given place, and evolving in an animal something which had no previous existence.

To say that these created things are the product of the forces of nature operating 


\section{Preface}

through the processes of reproduction, is to credit the maximum product to the minimum process. "A due consideration of it leads to the curious paradox that if any two animals be compared, the zoölogically lower will be separated from the common ancestor by a larger number of generations."

To say that intelligence is a function of the brain, is to say that the brain creates something out of nothing. The brain is clearly a mechanism employed in the process of making intelligence out of some pre-existing thing, but science has indicated nothing out of which it is made, or any work involved in the making. As far as our present science is concerned, the qualities which characterize man and the higher animals have come into existence from nothing, and are as much special creations as anything stated in biblical history.

Of course scientists do not really believe that something is produced from nothing. The revolution in thought which has come from establishing as a fact that modern 
animals are evolved from different animals through long lines of descent, and are not suddenly and independently produced by the fiat of a Creator, has attracted so much attention as to obscure the fact that the new view has changed the form without changing the substance of special creation.

The reasoning used in the following pages may be summarized as follows:

Animals of the present day exhibit greater intelligence and more physical strength than existed in their ancestors of earlier ages. The increase in intelligence from earlier geological ages to the present time is, in general, a gradual one extending through the generations and necessarily involving heredity. The question is as to how human intelligence got into man in the line of descent from man's ancestors. Or, more specifically, by what means did some men become inherently more intelligent than were any of their ancestors a few generations previously? Were the intellectual powers of these men the product of special acts of creation and consequently 


\section{Preface}

forever beyond human understanding, or were they simply results of discoverable processes of nature?

Intelligence is a manifestation of work performed in the brain. Work comes from energy, and if the energy in the brain is a special form of the energy we know in physical science, it must be subject to the same laws as other energy. The wide differences in the degree of intelligence exhibited by different men indicate correspondingly wide differences in the energy stored in their brains.

Energy is stored in a brain either by the fiat of a Creator or by some natural means. If it is stored by natural means, then that natural means must be work performed, and the amount of work periormed must be roughly proportional to the amount of energy stored. As the place of storage is the brain, the work of storing energy must be performed in the brain or in some organ directly associated with the brain. As no such associated organ is known, and as we know that 
intelligence is apparently increased by mental activity, it must be assumed that the work involved is brain work.

Work is measured by force, velocity, and time. The product of force and velocity may be represented by degree of activity, and by dividing the amount of work performed in some long period, as a century, by the number of years in the period, it is possible to determine the average activity per year. The year would then be the unit of time in measuring the amount of brain work performed in any period greater or less than a century.

In any long period covering several generations, the degree of mental activity becomes highly variable. It is zero during gestation and is maximum during adult life. The average activity, and consequently the energystoring work, is increased by increasing the proportion of maximum to the zero activity. Other things being equal, the amount of energy stored in the brain by doing brain work will be increased by lengthening the 
time between generations. If this energy is the foundation of intelligence, then intellectual power is built up through the generations in the offspring of comparatively old rather than comparatively young parents. Also, if this is the energy of intelligence, intellectual power is built up in the offspring of parents who were mentally active rather than in the offspring of parents who were mentally inactive.

Without at present going further into the reasoning by which this energy is applied to the successive generations of living organisms, it will be said that the age of the parents at birth of offspring is taken as the factor time in measuring work performed, and records for the kind and rate of work are taken to determine as nearly as possible the degree of activity. These are applied directly to individual cases and groups of cases to see if intelligence-producing energy is proportional to the amount of energy-storing work which was performed. The steps to this end lead through a consideration of muscular 


\section{Preface}

energy, and they extend to evolution in general.

C. L. R.

Monadnock Blocz,

Chicago, Illinois. 


\section{CONTENTS}

\begin{tabular}{|c|c|c|c|c|c|}
\hline \multicolumn{6}{|l|}{ PREFACE } \\
\hline I.-ENERGY & . & . & . & & \\
\hline II.-The Problem & State & & $\cdot$ & & \\
\hline III.-ENERGY IN AN & IMALS & & . & & \\
\hline IV.-HorsE-BrEEDIN & VG ME & Етн & & & \\
\hline V.-ThE $2:$ IO TRO & TTERS & & . & & \\
\hline VI.-EFFECTS OF TV & vo $\mathrm{GE}$ & NER & ATIONS & & \\
\hline VII_-English Sette & & . & . & & \\
\hline VIII.-HoLsteIN-FriEs & SIANS & . & . & & \\
\hline IX.-MAN & . & - & . & & \\
\hline X.-Longevity & . & - & - & & \\
\hline APPENDIX . & - & - & · & & \\
\hline BIBLIOGRAPHY & - & - & - & & \\
\hline INDEX & - & - & . & & \\
\hline
\end{tabular}





\section{Dynamic Evolution}

\section{CHAPTER I}

\section{ENERGY}

Natter and Energy Distinguished-Causes-Law and Rule Distinguished-Factors of Matter and EnergyDefinition of Energy-Conservatiun and Dissipatiun of Energy-Forms of Matter and Energy-Available Energy.

F primary things we know only Matter and Energy-space and time being simply factors in the measurement of matter and energy. Matter is a physical body which occupies space, has density, and offers resistance to cnergy. The word "Mass" is used to designate quantity of matter without respect to its shape, condition, quality, or density. Energy imparts motion to matter by overcoming resistance through a distance, 
and it exists in matter by virtue of such motion. Hence all motion involves energy. The expenditure of energy is represented by equal work performed, and work performed is represented by equal energy expended. Workand energy are often used synonymously, but work is in fact the act of transferring energy from one body to another. The fact of such transference is made evident by the changed relationship of bodies to each other. Because energy performs worls equal to itself, it is commonly defined as "stored work." Matter is inert. It is the "vehicle of energy," but does nothing of itself. The distribution of matter affects the distribution of energy, but all changes, motions, and transformations of matter are the effects of energy acting on or through matter.

Structure is matter in an organized form. It involves everything from the arrangement of atoms in a molecule to the bony, muscular, and nerrous systems of an animal. A bridge is a structure designed solely to resist strains. A machine is a structure which goes through 


\section{Energiy}

complicated movements by the application of outside energy. An animal is a structure which goes through still more complicated movements by the application of inside energy. The point here is that the size, shape, form, and color of an animal represent matter and not energy.

All things that happen are due to causes. As happenings involve motion, and as all motions come from energy, all causes are to be found in energy. Hence, energy is the same thing as the philosopher's First Cause, and includes what the theologians personify as God and Devil. Causes are either simple or composite, but whether simple or composite, a definite cause always produces definite and equal effects. A cause and its effects are different forms of the same thing, and are always equal to each other in amount. Hence, large causes produce large effects and small causes produce small effects or, in other words, effects are proportional to their causes.

Causes are forces acting upon matter. 
Forces act in straight lines,--curved motion being the resultant of two or more forces acting simultaneously on the same bodies. The magnitude of forces, the directions of their actions, and all resultants of two or more forces are subject to mathematical computations. Hence, all causes operate in accordance with mathematical laws. The mere fact that some composites of forces, particularly in living organisms, are so complex that they have not yet yielded to mathematical computation, does not negative this proposition.

A result may be the simple effect of a simple cause, or a composite of effects produced by a composite of causes. In any composite of causes, each individual cause produces its orm effect uninfluenced by the presence or absence of other causes, - the result being a composite of the effects. If a composite of causes is variable in its composition, the result is correspondingly variable.

The variability in animals is due to the variability in the composites of causes which 


\section{Energiy}

produce the results observed. Facts are observed results.

A law of nature is the mathematical relationship of a simple cause to its effect, from the statement of which it is possible to determine things, operations, and results otherwise unknown. From the perturbations of Uranus and the law of gravitation, Leverrier located an unseen and previously unknown planet. From the qualities of known elements and the periodic law, Mendeleëff described three primary substances then unknown to science, and gave their compounds, and the qualities of those compounds.

The laws of nature are of universal application, and consequently, there is no such thing as an exception to a law of nature. When we find an exception to a ganeralized statement, that exception is proof that the statement represents usual results from a variable composite cause instead of from a simple cause, and hence, that the statement represents a rule and not a law.

The distinction between a "rule" and a 


\section{Dynamic Evolution}

"law" should not be overlooked. When scientists find heterogeneous results, the causes of which are unknown, they formulate general statements which represent the most common results but which are subject to many exceptions. Such a statement represents a rule. When they reach causes and learn how those causes operate to produce the observed results, they formulate statements of laws which cover all possible results. That a given law operating in a uniform manner will appear to the uninformed to produce contradictory results, is a well-known fact. Thus, gravitation attracts bodies toward the center of the earth, yet a balloon rises, and it does so under the uniform action of gravitation. Similarly, the apparently contradictory results of breeding operations in animals may be shown to be due to the same law operating all of the time in the same way. The apparent contradictions are understood when the intervening causes have been determined and measured. The mass or quantity of matter in a body is the product of its Volume and Density. 


\section{Energiy}

As volume is the product of length, breadth, and thickness, we have

$$
\text { Mass }=\text { Length } \times \text { Breadth } \times \text { Thickness } \times \text { Density. }
$$

Inertia is a term used to express the fact that matter persists in the condition of motion or rest in which it is until that condition is changed by the action of energy. It is also used to represent the resistance which the mass of matter offers to energy.

Force is that factor of energy which serves as the immediate agency in giving motion to matter by overcoming its resistance. It is what we measure in pounds, grams, or any other unit representing strain or tension in matter. Other factors of energy are Velocity and Time.

A common formula used to represent the quantity of energy employed in doing work and also the amount of work performed by the energy is $\mathrm{K}=\mathrm{FVT}$, in which $\mathrm{F}$ is the force which acts to overcome resistance, $\mathrm{V}$ is the velocity of the force, and $T$ is the length of time that the force $\mathrm{F}$ continues to 
move at the velocity $V$. That part of this formula which is represented by FV is Power, which is defined as being the rate at which work is performed, or the quantity of work performed in a unit of time. Quantity of Energy is therefore the product of Power and Time.

Energy is also measured by a volume factor and a potential factor. Not that energy has volume in the sense that matter has volume, but energy is associated with matter, and when it is distributed uniformly through matter we may determine the quantity of energy by determining the volume of the matter and the potential at which the energy exists in this volume. The product of the two is the quantity of energy. Electrical energy is measured by amperes and volts, and the quantity in an electric current flowing over a conductor is mentally visualized by comparing it to water flowing through a pipe. In this case, the volts correspond to the pressure of the water in the pipe and the amperes to the volume flowing through the 


\section{Energy}

pipe in a unit of time. We, therefore, speak of electrical energy as being measured by volume and pressure. In a similar way we may illustrate the energy residing in the organs of an animal by comparing it with the quantity of air in a receptacle. In this case the quantity of air would be the product of its volume and its pressure. The quantity of energy in an organ would be the product of the volume of the organ and potential at which it existed in the organ. Or we may consider the cells of an organ as being so many accumulators (storage batteries) in which organic energy is continually being stored and from which it is discharged as wanted. The work performed by an animal is most easily measured by force, velocity, and time, while we obtain our best conception of energy within an animal available for performing work by considering its volume and potential.

The definition which states that energy is an attribute of matter is incorrect, because the amount of cnergy in a given body of 
matter may be increased or diminished at mill, or, theoretically, may be eliminated entirely without changing the mass of matter in the least, while an attribute is something characteristic of, or inherent in, a thing. If energy were a characteristic of matter, it could not be taken away without destroying the matter itself.

The definition which says that energy is "capacity for performing nork" is also faulty, as "capacity" indicates capability of receiving and containing, and hence gives the idea of cubical contents. Thus: Matter, occupying space, has capacity for storing energy, and the energy so stored may be used to perform work. "Ability" to do or perform anything gives the idea of energy without the accompanying idea of matter. To say that a person has the ability to do thus and so is equivalent to saying that he has the energy to do thus and so. The distinction between matter and cnergy is not only shown by the formulas for them but is recognized in ordinary life. The laborer who digs a ditch 


\section{Energiy}

recognizes the distinction between the thing upon which he works and the work he puts upon it. He sells his work but not his body.

The statement that thought is a function of brain is a special form of the erroneous statement that energy is an attribute of matter. The relationship of thought to brain may be represented by analogy. Send an alternating current through the primary of an induction coil, and an alternating current of a different quality comes from the secondary. This new current is not in any sense a function of the coil. It is the same energy as that which was first supplied, but it has been transformed by passing through a specific organization of matter. We may consider the brain as the induction coil of the living organism. Organic energy in passing through the brain is "stepped up" to that potential suitable for performing the work known as "thought," and this work is as distinct from the brain as the work of the induced current is from the wire in the induction coil.

The modern theory that matter and energy 
are, in their ultimate, one and the same, has nothing to do with our problem. Even if that theory be true, we are dealing with those situations in which matter and energy have been differentiated to that extent where they are no longer convertible into each other, and they have no common factors. Instead of considering matter and energy as the same, it would appear to be preferable to consider energy as an ultimate fact, and matter as a product of energy. Whatever produced or created matter must have been energy, because only energy can do things. If energy ever was created it required pre-existing energy to do the work of creating.

The first fundamental fact or principle of energy is that, while it may go through endless transformations and displacements, it can be neither increased nor diminished in total amount. In other words, it cannot be created or annihilated. This principle is known as the "Conservation of Energy." The "first law" of thermodynamics is founded upon this and is simply a statement 


\section{Energy}

that "heat may be measured in units of energy."

The second fundamental fact or principle is that energy equalizes itself by radiation from centers of high potential, and can be concentrated or stored only by the expenditure of other energy. This is analogous to the statement that water seeks a level and can be raised to a higher level only by the performance of work. This is known as the Dissipation of Energy. A special statement of this principle is known as the "second law" of thermodynamics, and is to the effect that "heat cannot pass of itself from a colder to a hotter body."

These principles have been recognized by science for such a length of time that it is no longer necessary to mention them except for the purpose of pointing out some fundamental error, or for the purpose of laying the foundation for a new argument. Both of these reasons for calling attention to these two fundamental principles exist in this case.

Both matter and energy take on many 
forms. Of matter, we know some seventyodd kinds. How many kinds or forms of encrgy there are we do not know. In the inorganic world we have heat, light, electricity, magnetism, chemism, and radio-activity. In the organic world we have life, growth, reproduction, muscular contraction, mental power, ability to produce results, nervous sensation, and a variety of others known under the general and somewhat vague term of vital forces. It is not material that we do not know what these things are, or that several of them may be the same thing under different names. All that is essential to our present considerations is that they are energy as distinguished from matter, and are to be measured by the factors for energy. Thus, the life in a living body is not measured by length, breadth, and thickness. By comparing a live animal with a dead one we know that it is life that gives motion to the body; hence, by definition, life is energy. Our inability to produce life from other forms of cnergy is due to our ignorance and not to 


\section{Energiy}

differences in essence. Animals familiar with heat and light are unable to produce fire, and man was familiar with electricity before he could produce magnetism.

Except in theory, energy does not exist separate from matter. The amount of energy existing in a body may be increased or decreased, but we cannot, by available means, take away from a body the total energy existing within it. That part of the energy in a body which may be used to perform work, is called available energy. How much energy in any particular body is available to perform work is not known in any case, but by experience we have learned that certain amounts are available and how we can determine those amounts. Thus, in an elevated weight, the available energy is the amount of work it can perform in falling to the surface of the earth. In the case of a man or a horse, the available energy is that which can be applied to perform work before exhaustion or weariness puts an end to the expenditure. Different inorganic bodies of 
substantially the same mass have different amounts of available energy accordingly as they are elevated to different heights, are differently heated, are differently electrified, or are moving at different velocities. Different animals of substantially the same mass have different amounts of available energy according to the amounts which are stored in their muscular or nervous systems. In all cases, the amount of work performed exactly equals the amount of energy expended, and by calculating the work we may determine the expenditure. Practically, however, some parts of the work performed fall into classes where it is not easily calculated except by refined scientific tests. The ratio between the useful work and the energy actually expended is called the efficiency. 


\section{CHAPTER II}

\section{THE PROBLEM STATED}

Distinction between the Organic and the Inorganic-

Organic Energy-H redity - Inside and Outside Energy-Increasins Energy in Horses-Process of Concentrating Energy in Animals--Great Individual Concentration Only in Old Animals-The Trotter Born yet Really Made-The Only Solution-" 2 : 10 Trotter" Defined.

THE main thing which distinguishes the organic world from the inorganic, the live animal from the dead one, and the efficient man from the inefficient, is energy and the potential at which it exists in the different bodies. This same difference in the concentration of energy distinguishes animals from plants, and the higher animals from the lower ones. The amount of work which any animal can perform represents its available energy, and availability depends upon potential. 
Another distinction between the organic and the inorganic is the extent to which we may practically extract and make use of the available energy. With inorganic bodies we may utilize the last particle of available energy which we can obtain, but not so with organic bodies. With organisms we must leave behind enough of the obtainable energy to keep the machine running, otherwise the organism will die or become wrecked as a further source of energy. A still further distinction is that organisms automatically replenish their supply of available energy. They are nature's machines for automatically storing energy in a form available for the performance of work.

In the organic world we find bodies having forms of energy peculiar to themselves, which energy acts to individualize the bodies with which it is associated. The energy in these bodies continues, but the bodies themselves are a combination of the periodic and the transient in existence. We may not know what these forms of energy are, but we are 


\section{The Problem Stated}

able to identify certain ones or combinations of them by the results produced. For convenience we may use the term "organic energy" as a generic term to designate those forms of energy which are associated with those bodies known as organic.

One of the phenomena of organic energy is reproduction, by which the identical forms of energy are started into operation in new bodies, after which the organic energy in the previous bodies becomes dissipated, and those bodies cease to exist as individuals. The new bodies take on the same form and structure as the previous bodies, and the new bodies with their associated cnergy become new individuals. The result is that while the individuals are ephemeral in existence, the same forms and structure of matter and the same kinds of energy persist through successive generations of individuals.

That principle of nature by which the same form and structure of matter and the same kinds of energy persist through such a complicated process as reproduction is known 
as "Heredity." The fact that heredity represents the persistence of matter and energy through successive generations in their previous conditions makes it analogous to, if not identical in principle with, what is known as Inertia. It is an observed fact that while the individuals of one generation are like those of the next, the likeness does not amount to identity. Differences may be seen and measured. It is also an observed fact that the individuals of each generation are subjected to different and varying actions of energy before reproduction. The energy here involved is principally, if not exclusively, that which is within and operates through the organism. It is that ener $y$ which is implied when we speak of the dynamic development of an animal. Outside energy which is of insufficient magnitude to overcome the inside energy known as "life" appears to have no direct effect upon the resistance linown as heredity. A consideration of the indirect effect of outside energy involves a complexity which is avoided as not being necessary to 


\section{The Problem Stated}

the present purpose. If nature's laws are uniform in operation, such variations in the action of energy must necessarily produce variations in individuals. Also, if nature's laws are uniform, such variations in individuals necessarily imply the action of energy to produce them. A measurement of the amount of change in individuals from one generation to the next, divided by the change in the application of energy, should furnish a numerical value for the resistance of heredity. A sorting process in reproduction by which some things are included and others omitted is not a change, and does not involve the expenditure of energy except inasmuch as the sorting action involves it. Likewise, the suppression of a secondary sexual character in that sex in which it normally does not appear, represents a difference in form of energy, or the temporary closing of a channel through which energy flows, and not a change in the amount of energy.

Occasionally we find an animal which, at some particular age, possesses a greater quan- 
tity of available energy, or available energy at a much higher potential, than existed in any of its ancestors at the same age, two or three generations previously. For example, a horse is capable of trotting very much faster than any ancestor, a cow is capable of producing a greater quantity of milk in a given time than either granddam, and a man has mental capabilities far beyond those of the parents of either his father or his mother. Or, to be more specific, take a modern trotting horse which is able to trot a mile in less than 2 : Io. That horse had two parenis, four grandparents, and eight great-grandparents. As far as "blood" is concerned, that horse is a composite of those great-grandparents, and he is largely such as far as his physical structure is concerned. But his available energy, at say five years of age, is not similarly a composite or average of the energy of his great-grandparents at the same age. Not only is his available energy greater than the average of those ancestors, but it is greater than that of any one of them. 


\section{The Problem Stated}

Let us state the matter in another way. At the beginning of the nineteenth century the extreme trotting speed was a trifle slower than a mile in three minutes. At the beginning of the twentieth century the extreme speed was a trifle faster than a mile in two minutes. The available energy in the horse of to-day is greater than that of the horse of a century ago by a ratio somewhat greater than the square of three to the square of two. The ordinary horse generation is ten years in the male line, but the particular line through which we get our two-minute trotters averages about fourteen years per generation. This makes seven generations in which to make a gain of a little over a minute, or an average gain of nine seconds per generation. The gain in speed, and consequently in the amount of available energy, is not quite uniform, but the general trend of it may be observed from the following table, which gives part of the champions at different dates, and the records they made. 


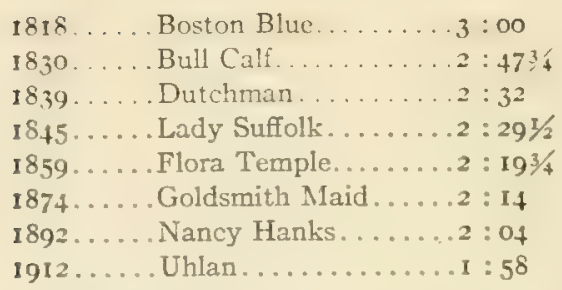

The general trotting stock used for breeding purposes was, of course, much behind these extraordinary animals at the time they made their records. The fact that from this general stock we have been getting, from time to time, faster and faster horses, until now we have many animals capable of trotting a mile in $2:$ Io or less, shows clearly that each generation of horses has inherited more energy than the preceding generation by an amount which is represented by an average gain of nine seconds per generation in trotting a mile.

Whence came this increase in amount of available energy? How did it get into successive generations of animals at higher and higher potential? "You can't get something from nothing." Energy must be put into a 


\section{The Problem Stated}

horse before it can be found there, and it requires work to do the putting. What work associated with the different generations was performed to produce this concentration of energy?

When energy exists in any body at the same potential that it exists in similarly situated bodies, there is nothing to excite surprise or cause comment. The fact that energy tends ever to equalize itself is a sufficient explanation of uniform and equal distribution. But when a body is found which has energy at a higher potential than that at which it exists in other bodies, something has occurred which demands explanation. When it was discovered a ferv years ago that radium maintained itself continuously at a higher temperature than that of the surrounding medium, Lord Kelvin remarked that for the first time a question mark had been placed opposite the doctrine of conservation of energy. That question mark, however, remained at that place a very short time. The situation was so remarkable that 
physicists applied themselves earnestly to discovering the cause of this phenomenon, with the result that they quickly learned the source of that energy.

Any animal which has and maintains within itself an amount of energy much in excess of that which exists in other animals of the same class is just as remarkable as radium, and calls just as loudly for an explanation of the source of his energy. The fact that such cases are of frequent occurrence should not blind us to the fact that science has something of importance to investigate. Whatever may be the answer, it should not deny the uniformity of nature's laws. Sound science demands that the first efforts at an explanation should be along the lines of previously established facts and principles. If these do not suffice for an cxplanation, then we may try other explanations, but a mere denial of their sufficiency will not do. In the absence of a showing to the contrary, it is to be presumed that the facts and principles of nature which are established in one 


\section{The Problem Stated}

science are universally true and cover similar facts and principles in all sciences. To establish the contrary requires demonstration of the most conclusive character.

In the present case we have an extraordinary concentration of energy within a single body - a fast trotter, - and that concentration must have occurred in strict accordance with nature's laws. Physicists have studied energy in its transformations through many and various forms and have established the doctrine that it can be neither created nor annihilated, and the fact that it can be concentrated or stored only by work, - which is the expenditure of other energy. Until conclusive evidence to the contrary is furnished, it must be presumed that these are universal in their application.

We have our animal with an extraordinary accumulation of energy over what existed in previous generations. That energy is drawn from food, but its concentration to a potential higher than that at which it exists in the food must have been accomplished by the 
expenditure of other energy. The mere feeding of an ordinary horse will not make him into a 2 : ro trotter. What energy was expended, and how was it expended to produce this 2 : Io trotter?

We know of but one process by which available energy can be concentrated in a living organism, and that is by expending energy through the organs within which it is intended that the concentration shall take place. This is exercise, and the lind of energy stored is identical with the kind of work performed. We use it on the track and in the gymnasium to concentrate energy in the muscles, and in the schools to concentrate it in the brain. We may not know the details of the process by which the concentration is brought about, but we know the fact that such concentration results from such expenditure. We also know that the available energy existing in a living organism will decline (become dissipated or leak away) if not continually replenished by exercise. The idle animal becomes the weal: animal. 


\section{The Froblem Stated}

In this concentration and dissipation of animal energy, time is always a factor. Omitting the two extremes of infancy and senility, we may say that if the concentration uniformly exceeds the dissipation, or the dissipation uniformly exceeds the concentration, the total gain or total loss may be determined by considering the age of the animal. The maximum amount of concentration which can occur in any animal is, therefore, limited only by the rate at which the concentration takes place and the age of the animal at which the process ceases or is interrupted. Or, stated in another form, a very great accumulation of energy within an individual made directly by this process of concentration, can exist only in comparatively old animals. This should not be taken to mean that an animal has a large amount of energy simply because it is old. The statement that man is an animal does not imply that an animal is a man.

In what precedes is stated a process by which energy is concentrated within an ani- 
mal, the factors by which the positive or negative amount of concentration may be calculated, and the conditions which must be fulfilled to have this concentration the maximum within the life of a single individual. This theoretical maximum is never obtained in practice: first, because the rate of concentration is never at its maximum for long periods of time; and second, because net gain is usually changed to net loss at a greater or less length of time prior to that time in life at which net gain must necessarily cease.

But feeding and training an ordinary horse will not make him a 2 : Io trotter. Like the poet, the 2 : Io trotter is born and not made. Being "born" must not be construed to mean that because he is not made in one generation he is actually not made at all. It will not do to waive the matter aside by the statement that the animal is born and not made, and thus assume that encrgy was either created or accidentally concentrated in the reproductive process. We must go further in tracing the source of that energy. 


\section{The Problem Stated}

The assumed 2: Io trotter accumulates energy by being trained, but the amount of his eneryy is more than the ordinary horse can obtain in this way. It is also more than any ancestor had. It must, therefore, be the sum of what he received from his parents, plus what he accumulated. But that is the case of every horse not capable of becoming a 2 : Io trotter, consequently he must have received from his parents more energy than is received by the ordinary horse. It goes without saying that parents cannot transmit more energy than they have, and the principles previously stated preclude either creation or accidental concentration. Calling the thing transmitted by some other name, as "ability," does not evade the issue, because ability comes from energy and is measured by energy. Hence, the parents themselves must have had more energy than ordinary parents.

This removes the difficulty one step but does not solve the problem. We cannot push back the question step by step to the assumption that the earliest ancestors had as much 
energy as the immediate parents. The logical results of such a procedure would be to wipe out the doctrine of evolution and reestablish special creation. Even the assumption of special creation with as much energy at the beginning as at the end would not solve the problem, because energy normally dissipates, and once dissipated it can be reconcentrated only by work.

There is but one solution, and that is that the parents themselves must have accumulated by work more energy than they dissipated by idleness, and must have transmitted this accumulation to their offspring. But the 2: Io trotter has such an extreme excess of energy over and above that of the ordinary animal that his accumulation plus the accumulation of his parents will not equal the possession. To obtain an accumulation equal to the possession, the grandparents must have accumulated more than they permitted to dissipate, must have transmitted that accumulation to the parents, and the parents must have added their own accumu- 


\section{The Problem Stated}

lation to what they received, and then passed the entire amount to the offspring, who added to this sum his own accumulation. In fact, a comparison of extraordinary animals with the amount of energy accumulated by an ordinary contemporary animal in a rather more than normally active life indicates that we should go back to the great-grandparents and the great-great-grandparents for part of the excess over that which exists in the ordinary animal of the same breed.

To account for the energy existing in such an animal as a 2:10 trotter coming from stock not having that capability, it is evident that we should consider the accumulations of two or three generations previous to the animal itself. The fact that accumulations of animal energy dissipate rapidly by reason of idleness, and the additional fact that animals used for breeding trotting stock are frequently idle animals, makes it evident that ordinarily such accumulations must exist within two or three generations of an animal of 2 : Io quality. It does not follow 
that there was necessarily an accumulation of energy by the parents to produce a 2 : Io trotter, as those parents may have worked only enough to have preserved from dissipation that which they inherited, and that inheritance may have been enough to have furnished a foundation upon which 2 : Io quality could be built. What cannot exist, however, is an animal of 2 : ro quality coming from parents and grandparents which permitted more energy to dissipate than they accumulated up to the time they reproduced. To assume that such an animal as that could exist is to assume that energy can be concentrated without the performance of work to produce such concentration, and to find such an animal would be to overthrow the established doctrine of encrgy".

The term " 2 : Io trotter" is used to represent an animal with an unusual quantity of energy at a high potential, and not either alone. A large animal may have a large amount of energy ly reason of its bulk, and not much be available for work because of 


\section{The Problem Stated}

low potential. Another animal may have a high potential in a particular line but a small total quantity of energy. There are a few rare instances of horses attaining $2:$ 10 speed but without vitality or energy of other kinds. Such animals are like the "genius" who does one brilliant thing and then goes to the madhouse. Such individuals are cases of unbalanced distribution of energy, probably due to defective organization. A horse may attain 2 : Io speed and yet not be of $2: 10$ quality,-the 2 : Io quality being intended to represent an animal superior to its ancestors and capable of expending a large amount of energy in worli and still have enough reserve energy to prevent it from collapsing as the result of such expenditure. The cow which produces many more pounds of milk per day than was produced by any one of her great-granddams may be considered the 2 : Io trotter of the dairy. From the intellectual standpoint, Bacon, Franklin, and Humboldt may be considered as $2:$ Io trotters of their times. 


\section{Dynamic Evolution}

That animal energy is being continually dissipated is a fact of observation, seen by noting that an idle animal becomes weak.

That a certain amount of energy is consumed in keeping the animal machine in operation is a second fact of observation, seen by noting that even an idle animal must be fed or it will die.

That energy is concentrated in a living organism by the expenditure of previously. existing energy of the same lind in the form of work or exercise is a third fact of observation familiar to all trainers.

That animal qualities persist with uniformity through successive generations is a fourth fact of observation, seen by noting that horses come from horses, goats from goats, rabbits from rabbits, etc. 


\section{CHAPTER III}

\section{ENERGY IN ANIMALS}

Se ondary Sexual Characters-Period of Gestation-Certain Characters at Certain Ages-Transformed Energy-Delay in Concentration-Concentration Proportional to Expenditure-Dissipation of Animal Energy-Testing Pedigrees for Concentration of Energy-Lines of Limitation.

$S^{O}$ far, the general principles of Physics (known as the science of energy) are the same in biology as they are in mechanics. The difference between biology and mechanics lies in the difference in the manner of applying these principles and not in the principles themselves, or in the manner of measuring the energy involved in the principles. Before we turn to the facts of record for the purpose of determining the accuracy of the reasoning and conclusions previously set forth, it is necessary for us to consider a 
few of the things which are special to living organisms and which consequently influence the application of the principles.

In animals generally, and in the higher animals particularly, we have what are known as secondary sexual characters. These are those characters by which the sexes are distinguished from each other, and which are not directly involved in the reproductive process. They include such things as size, shape, extra appendages, color, voice, and habits. The general facts in regard to these characters is that they first appear after sexual maturity and are confined to individ. uals of one sex. It is highly probable that this statement may be broadened into the statement that any character or quality which is developed in an individual after sexual maturity is a secondary sexual character, and is primarily transmitted only to offspring of the same sex as that in which it was first developed.

The beard on the face of man is one of the best known of secondary sexual characters. 


\section{Energiy in Animals}

It develops after the boy has reached sexual maturity, and a consideration of the manner in which it is transmitted through successive generations will illustrate the transmission of secondary sexual characters in general. The father has a beard, and though the daughter inherits other characteristics from her father, she does not inherit his beard. Yet that daughter's son may have a beard like that of his maternal grandsire. In this case, the son inherits a peculiar form of beard from his mother, who had no beard at all. Hence, though we speak of a secondary sexual character peculiar to the male as being absent in the female, it is suppressed rather than absent in essence. Similarly a bull transmits to his daughters the milking qualities of his dam, though he had no milking qualities of his own.

There is nothing in the science of physics which would classify energy accumulated during the adult stage as being a secondary sexual character, but the biological fact that numerous animal functions are secondary 
sexual characters requires us to keep that point in mind and not to place factors in equations where they do not belong. As it is energy which causes characters to grow, we may argue that the energy which causes the beard to grow on the face of a man must be, in some way, different from the energy which fails to cause it to grow on the face of a woman. Hence, those things which re call secondary sexual characters are simply products of an energy which has a sexual relationship, and it is the energy and not the observed character which is (secondary) sexual.

Arresting sexual development by castration is known to arrest the development of secondary sexual characters. The eunuch develops neither a beard nor a bass voice. In trotting horses, castration is largely practiced, and geldings form a large part of standard performers. In examining trotters it is therefore necessary to divide them into three groups,--stallions, mares, and geldings. As pointed out before, age of animals is time, 
and time is a factor in the measurment of energy. If energy concentrated in the organs of an animal by work performed after sexual maturity has a sexual character, then it would be obviously improper, in considering the inherited energy of a stallion, to measure by the age of his dam, and it would be equally improper to use the age of the sire when the animal considered is a mare. When it comes to geldings, questions arise which require that they be placed in a class by themselves until investigation shows what relationship they have to sexually perfect males and females.

In mammals, the period of gestation is a resting stage during which there is little or no energy accumulated by reason of outside work performed. The dissipation of energy, however, continues through this resting stage, with the result that the young animal has less energy than the parent, and arrives at the parental quantity of energy only after a considerable amount of wort has heen performed subsequent to birth. How much 
work it is necessary to perform in restoring the energy lost by dissipation during gestation and early infancy, can be determined only by an investigation of the facts. Our present knowledge is not sufficient for us to reach it by theory. What effect the expenditure of energy in growth may have upon the dissipation or accumulation of energy capable of being used to perform outside work, is a refinement not gone into because there are too many opportunitics for making unwarranted statements. Besides, as it is quite possible to determine the general facts without considering this point, there is no reason why we should add this complexity to an already complex problem.

In animals generally there is a tendency for characters (not necessarily secondary sexual) to develop at certain ages in individuals of successive generations. This tendency for a character to develop at the same age in each generation, appears to be associated with the growth of the individuals. In the absence of precise information to the 


\section{Energy in Animals}

contrary, it is a wise precaution to assume that energy, accumulated at a given stage in growth or cellular change, will tend to confine itself to that stage and will resist change to a different stage. All resistance, however, will yield to the application of force, and the amount of yield will vary directly as the amount of energy expended and inverscly as the magnitude of the resistance. From this we may argue that if the energy expended to produce an accumulation comes at a different time in the life of an individual from that at which it came in the preceding generation, this change in the application might force the inherited accumulation toward the new time in life. Hence, if a stallion accumulated a large amount of energy by reason of a large amount of work performed shortly after becoming sexually mature, and that accumulated enery became sexual in character by reason of the time in life at which it was accumulated, then if the son of that stallion should perform a large amount of work before becoming sexually 
mature, the inherited energy might be pushed forward into the immature stage, and what started as a secondary sexual character might become an ordinary character and be transmitted to offspring of the opposite sex. The facts of physics and biology make it a wise precaution to take this into consideration, and the facts of pedigree records show that a failure to consider it would result in confusion and misinterpretation.

This possible shift of characters might be of relatively small importance when the energy characteristics are practically uniform for all individuals in successive generations, but it assumes very great importance when periods of work and idleness are highly variable both ats to degree and time in life when they occur. With trotting horses these are extremely variable. Some horses do hard work nearly all their lives, other horses work hard at one age and are idle at other agres, other horses have the times of work and idleness reversed, and still other horses are idle nearly all their lives. In any horse pedicree, 


\section{Energiy in Animals}

the kind and amount of work performed and the time in life when the performance occurred, are essential to the determination of what possible effect his accumulated energy may have on his descendants.

Although expending energy through an organ concentrates energy in that organ, the concentration does not occur immediately. upon the expenditure. A little time is required to produce the physiological result of concentration within the organ. Likerrise, if a physiological result in an organ be reflected in the germ so that concentrated energy may be transmitted to the next gencration, that fact rould require the lapse of some time. Consequently, in applying the facts of pedigree records to test the theoret ical conclusions previously given, there should be a certain time allowance between the work performed and the beginning of the reproductive process. What this time allowance is, is not known, and probably it would be difficult to determine it because of the complexities involved, but it has been roughly 
estimated at from five to ten per cent. of the age of the animal at time of reproduction.

We know that using an organ to perform work concentrates energy in that organ so that it improves in its capability of performing work. We also know that, within limits which will be discussed later, the more an organ is used the more energy will be concentrated. An athlete or a horse is trained for a long time before he is fit for his trial of strength and endurance.

If, after an animal has been trained for a considerable time, further concentration of energy ceases by reason of the animal becoming and remaining idlc, the previously concentrated energy will dissipate in accordance with the general law of the dissipation of energy, and the animal will become weaker. How much energy will be dissipated will depend upon the degree of idleness, the length of time the idleness continues, and the nature of the concentration.

The available energy in an animal is measured by its rolume and by its potential, 


\section{Energiy in Animals}

very much as electrical energy is measured. The quantity is a product of the volume and the potential. A high potential comes from extreme activity, and large volume comes from a long time during which concentration occurred. The rate at which energy dissipates under a given degree of idleness is proportional to its potential, much as the rate at which heat radiates from one body to another is proportional to the difference in temperature of the bodies.

If a quantity of energy be concentrated in an animal at a high potential by reason of extreme activity continued over a short period, a considerable degree of idleness will permit the concentrated energy to dissipate rapidly. If the same quantity of energy be concentrated at a less potential by a less degree of activity extending over a longer period of time, then the same degree of idleness will not permit such a rapid rate of dissipation, and it requires longer for the animal to lose the same amount of energy in the second case than in the first. The perma- 
nence of a dynamic development is proportional to the length of time involved in its acquirement.

We may illustrate the concentration of energy by considering a horse being trained as a trotter. During the early part of his training he gains speed rapidly, the amount of gain being represented by the length of time required, in minutes and seconds, for him to trot a mile. This gain in speed is called development, and it is the ordinary but inaccurate practice to represent a horse's development, by his trotting record. A time comes in the training of a horse when no further work will add to his speed. It is then said that he has reached the limit of his development, but a little consideration will show that this is not true. While a horse may not gain in speed by further training, he gains in endurance and can trot a greater distance without exhaustion. As it requires more energy to trot the greater distance, it is evident that the additional work performed has added to his accumulation of energy, 


\section{Energy in Animals}

and that this accumulation is by volume rather than by potential. There also comes a time when further training will add nothing to his endurance, but even this does not end his dynamic development. If an animal has been trained only a short time, his energy will dissipate rapidly by idleness; if he has been trained longer it will take longer for his energy to dissipate to the same extent by the same degree of idleness; and if we examine the matter carefully we will see that the time required to dissipate accumulated energy down to a given point by a given degree of idleness is closely proportional, if not exactly proportional, to the length of time involved in its concentration. Also, that this proportional relationship goes beyond the point where individual endurance is increased by additional work performed, and clearly indicates that such additional work causes an additional concentration of energy which is apparent by observing the quantity dissipated. There must be a concentration before there can be a dissipation. Hence, old ani- 
mals which have worked hard and long are more likely to have their accumulations of energy persist through two or more generations than younger animals. In other words, when animals are selected because of their inherited energy as it becomes apparent in their power to "breed on," the elimination should be of the progeny of young sires and the preservation of the progeny of old sires.

By experiments and tests, formulas have been constructed for calculating the concentration and dissipation of heat and electricity. Observation shows that animal energy behaves in concentration and dissipation in a similar manner, if not in the same way, that heat energy and electrical energy behave. They are different forms of the same thing, and the uniformity of nature's laws requires that they act in the same way except inasmuch as the difference in forms may involve differences in the applications of the actions. It is highly probable that after proper tests and experiments have been made formulas will be constructed for animal energy which 


\section{Energy in Animals}

will be very similar to those constructed for heat and electricity. While we do not have formulas for the rate of concentration and dissipation of energy which we can apply to the different animals in a pedigree, still, by observing the principles involved and taking cases so pronounced and so well recorded that there is no excuse for overlooking what occurred, we can determine the main facts of how energy is accumulated through the generations.

In applying these principles to the animals in the pedigree of a trotter for the purpose of determining whether energy accumulated in a previous generation is transmitted to the next, we look first into the dynamic condition of the sire. We estimate the volume and potential of his energy from the work he did. If the trotter is a stallion, we look at the dynamic condition of the sire as it existed a short time before reproduction. If the trotter is a mare or gelding, we look at the condition as it existed in the sire at three years of age. In determining this dynamic 
condition we examine the history of his activities and his idlenesses, their sequences, the lengths of time during which each occurred, and the relationship of those occurrences to the stopping point at which dynamic condition is to be determined. If we know what have been the normal activities of stallions in breeding establishments up to the average stopping point, we have a fair mental conception of what this dynamic condition is as compared to the average dynamic condition of sires. We are able to say whether the paternal concentration of energy is positive, or negative, or neutral. If it is a pedigree of a 2 : Io trotter that we are examining, theory demands that the concentration shall not be negative. If the trotter is a 2 : Io stallion, it will be negative if the sire is as young and as lacking in training as is frequently found in the sires of 2 : Io mares and $2:$ Io geldings.

In the case of the dam of a 2 : Io mare, we look for the dynamic condition of the dam a.; it existed just before reproduction. If the trotter is a stallion or a gelding, we look for 


\section{Energy in Animals}

the dynamic condition of the dam at the age of three. With this dynamic condition determined with as much accuracy as the facts will permit, we can compare it with the average dynamic condition of brood mares as it is known to exist in breeding establishments, and from this comparison can deternine whether the maternal concentration was positive, negative, or neutral.

This is the first step in examining into the nuanner in which energy is or may be concentrated in a 2 : Io trotter. The second step $i$ i; to make a similar examination, properly modified, into the concentration by the grandparents. If the trotter is a stallion, the two grandsires are examined in the same way that the sire of a stallion is examined. If the trotter is a mare or a gelding, the maternal grandsire is examined and estimated in the same way that the sire of a mare or gelding is examined and estimated, but not so with the paternal grandsire. In this case we divide the grandsire's concentration into two parts, - that which is an ordin- 
ary character by reason of being accumulated before sexual maturity, and that which may be a secondary sexual character by reason of being accumulated during the adult stage. If there is a considerable accumulation which may possibly be secondary sexual, we look to the early activity of the sire (this grandsire's son) to see if that activity was of a kind that might transform a secondary sexual character into an ordinary one. If so, we add it to the inheritance of the mare or gelding. If not, we omit it.

Having due regard for the relationship of the sexes and the possible existence of secondary sexual characters, we examine the granddams in the same way that we examine the grandsires. If the trotter is a mare, the two granddams stand on the same footing as the dam of a mare. If the trotter is a stallion or a gelding, the paternal granddam is cut off at three years of age, and the maternal grandiam is cut off or extended to actual age of reproduction accord- 


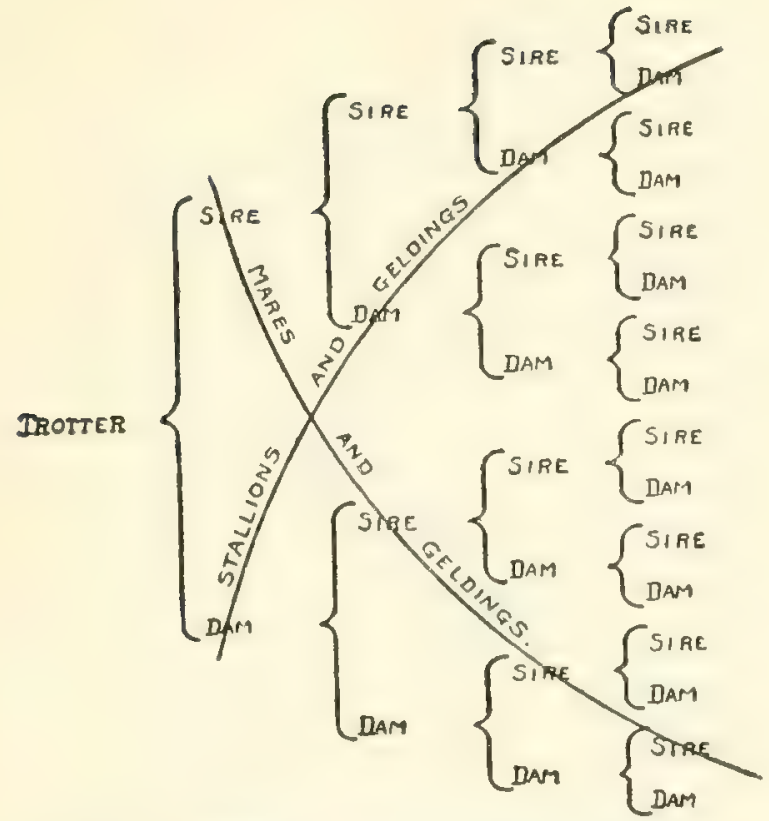

Lines of Limitalion. If "Trotter" is" a female or a "gelded" male, then no energy acquired by the sires in the line "mares and gelding:" after they have become sevually mature will affect the individual energy characteristics of "Trotter." If "Trotter" is a male, then no energy acquired by the dams in the line "stallions and geldings" after sexual maturity will affect the individual energy characteristics of such male. 


\section{Dynamic Evolution}

ing to what was the early activity of the dam.

These two steps usually tell the story with a fair degree of certainty, but they are not conclusive, as conditions may exist in which all of these animals are neutral, or so nearly neutral that it would be impossible to determine the facts. We therefore take the third step by examining the great-grandparents. The paternal grandsire's dam stands on the same footing as the dam and the sire's dam, and the maternal granddam's sire on the same footing as the sire and the dam's sire. The other great-grandsires and great-granddams have the same standing as the sire's sire and the dam's dam.

As three generations of ancestors of our 2: 10 trotters take us back to a time when there was no horse in the world with energy enough to trot a mile in $2: 10$, an examination extended thus far in detail, and with the care and particularity indicated, is conclusive in determining whether energy came into these horses in accordance with 
the theory advanced, or in some other way.

It may also be said that any investigation which fails in tracing energy with this thoroughness will fail in conclusiveness. 


\section{CHAPTER IV}

\section{HORSE-BREEDING METHODS}

Large Farms-Race Records-Roadsters-Stallions and Mares-Fertility Impaired by Racing-Prejudice against Horses with Race Records-Small FarmsUncertainty in Brceding Trotters-Hambletonian's Sons-Number of Progeny by Raced and Non-Raced Horses-Ages of Sires.

THE American trotter has been bred in all parts of the country from the Atlantic to the Pacific, and from Canada to the Gulf of Mexico, and under all kinds of conditions and circumstances. To apply the principles of energy to pedigree reading, it is necessary to review and classify these conditions so that we may properly estimate the value of any particular fact when we come across it associated with any of the progenitors of the animals being investigated.

At all times, for nearly a century, there 


\section{Horse-Breeding Methods}

have been large establishments devoted to breeding the trotter. During the same time there have been racing associations with race tracks in nearly all parts of the country, and the horses used for racing purposes have been transported, principally by railways, from track to track during the racing season. The breeding of trotters and the racing of trotters are distinct businesses, and the same man has rarely been interested in both at the same time. The large breeders, however, have usually had short tracks of their own on which they have trained youngsters for the market. Professional drivers have made it a practice to frequently visit breeding establishments, large and small, for the purpose of securing youngsters likely to make winners on the race track. The drivers have talien these animals to their own tracks, have trained them, and then have used them for racing purposes for one or more seasons as policy or circumstances might dictate. The best of them are raced on the Grand Circuit, those of lesser speed find their way 
60 Dynamic Evolution

to the half-mile tracks, while those which do not develop winning qualities are discarded.

One of the peculiarities of the racing business is that if a horse develops remarkable speed at an early age, or in a short time, he is barred by his record from opportunity to get into profitable races, with the result that such a horse is rarely raced more than one season. As a general thing, remarkable natural trotters have not done much trotting. A few exceptions make the general proposition stand out clearly.

Another peculiarity is that a trotter does not get a record because of his ability to trot in record time, nor even because he actually does trot in record time. Many horses have trotted a mile in a race on a race track in less than $2: 30$ without obtaining a record. A horse gets a record only when he crosses the line ahead of all competitors in the race. An exception is the so-called "tin-cup record" obtained when a horse trots by himself in record time under certain specified condi- 


\section{Horse-Breeding Methods}

tions. A record indicates that a horse has been trained and raced, though frequently only to a small extent, but the absence of a record does not prove the absence of $d y$ namic development. Many highly developert stallions and mares never had race records.

Until recent years it has been the practice to use as carriage horses or roadsters those horses which have been on and have retired from the race track. Wealthy men of sporting proclivities have bought up large numbers of retired racers and have maintained large stables of them for no other purpose than their own amusement. The result has been that, prior to about I900, a very small proportion of those horses which were campaigned on the race track later entered the breeding establishments. These earlier conditions are those which interest us, because that is the time when the parents and grandparents of our present trotters lived.

Persons interested in brceding the trotter usually have large numbers of brood mares and several stallions. Brood mares spend 
their summers in the pasture and their winters in the barn. In large establishments they are not required to work, and many of them never wore harness. The stallions of a breeding establishment spend their lives in specially constructed box stalls to which are attached individual paddochs some thirty or forty feet square. In such conditions they get no exercise other than that which they take voluntarily. A small minority of breeders have gone to the expense and trouble of exercising their stallions a short time each day. In a few cases this exercise has amounted to as much as driving the stallion from five to seren miles per day, mostly at a jog trot, with a half-mile or so of comparatively fast trotting.

In the large establishments where several stallions are kept, these usually range from the most highly prized individual, which is given every care and attention and is bred to the choicest mares, to the "dung-hill," which is required to do farm drudgery and is bred to scrub stock at a nominal fee. The 


\section{Horse-Breeding Methods 63}

strong contrast in the treatment given these stallions on large breeding farms makes a great difference in the amount of energy they acquire by work performed, and the appearance of one or the other kind in the best pedigrees as they are found some thirty or forty years later is both interesting and instructive.

Up to about $\mathbf{1} 890$, and to limited extent up to the present time, there has been a strong prejudice among breeders against using for breeding purposes those stallions and mares which had also been used for racing. The theory was that the strain of racing impaired the vitality of the horse and ruined it for breeding purposes. This theory is based on the fact that mares which have been a long time on the race track frequently prove barren, and the fact that stallions which have been raced hard are not good foal getters until after they have been retired for two or three years. The impairment of fertility was construed to mean the impairment of vitality. The maxim was "breed to the blood 
of the winner," and not to the winner himself. As late as 1905 , a breeder told me that he would not keep a brood mare which had ever worn harness, and that he would have nothing to do with any stallion that had ever been raced. The same breeder said further that he would not accept as a gift the stud services of the horse which was then the champion stallion of the world. Views of the same character, though less extreme, were frequently expressed in some of the horse papers at an equally late date.

There are many things in horse literature which show the prejudice of breeders against using for breeding purposes those stallions which went to the race track, but perhaps the best way is to go to the stud book (technically known as the Trotting Register) and see what it was that the breeders registered and what they neglected to register. Hambletonian ro was the founder of the leading family of American trotters, and his merit was recognized before he reached middle life. He had ten sons which went early to the 


\section{Horse-Breeding Methods}

race track and secured records, and somewhat over one hundred and forty sons which did not. Before Hambletonian was ten years old, his grandsons and granddaughters were much in evidence. Thirty years after Hambletonian was born, five of those ten horses which went to the track had no registered male offspring, if they had any offspring at all. The other five with records had a total of 28 sons registered, 12 of which were sons of George Wilkes, then 23 years of age. Part of the sons without records were at the same time represented by $7+7$ registered male offspring. Thirteen of Hambletonian's sons without race records had 273 , or an average of $2 \mathrm{I}$ each. These thirteen sons were undoubtedly, at that time, considered the most valuable of Hambletonian's offspring. Contemporary publications so represented them. By the irony of fate, these thirteen valuable stallions and all of their descendants are practically extinct as far as the best trotting pedigrees are concerned.

Large numbers of trotters are produced by 
farmers who keep from one to four or five mares. In such cases the mares do ordinary farm work, and are used on the road driving to and from market. These mares are usually bred to neighboring stallions, but sometimes are sent long distances to be bred to stallions of fancy blood. Some men in various walks of life keep stallions which they use for breeding purposes in their neighborhood and also for driving on the road. Such stallions usually get more trotting work than any others except those for a long time on the race track. Some of them have been "abusively" driven. There are many cases in which a man keeps one stallion to which he gives his whole attention, and which he mores about the country from place to place. Such men rarely drive their horses. If a railmay is not convenient for their transportation, they are led. Some "vicious" stallions have been lept in chains without exercise for years, while others have not been driven for fear they might be injured.

Finally, there has been a small class of 


\section{Horse-Breeding Methods}

67

sporting men who have traveled about the country from place to place with one or a few horses and who have violated all of the ethics of racing, breeding, and humanity. They have fixed up fake races through which they robbed the farmers of their money; they have raced their horses unconscionable distances with unconscionable frequency; they have bred these animals to anything that pleased their fancy; and they have put very young colts under such terrific training or abuse that their work has been called "the slaughter of the innocents" and the ruin of valuable stock.

During the formative period of the trotting breed, and when railways were not so common as they are now, there were many men, not connected with breeding, whose husiness required them to travel about the country from place to place, and who used horses for this purpose. Some of these horses were mares which subsequently went into the breeding ranks and are now known in breeding history as "road mares." The amount of 
trotting rork some of these road mares did before being bred is quite surprising. Being driven from twenty to thirty miles per day was not unusual, and there are cases known of such mares being required to travel more than one hundred miles in one day. A mare which does this kind of work for ten or twelve years may be considered as well developed from the dynamic standpoint.

What ones of these breeding operations do we find frequently in the grandparents and earlier progenitors of our 2 : 10 trotters, and what ones do we never find there? They represent all kinds of breeding experiments, from the cxtreme of activity to the extreme of idleness, and extending across a continent and over a century of time. From twenty to fifty years after the breeding of these diverse and intermingled experiments, the descendants are submitted to breeders who form their judgments from what is occurring at the time on the race track and who give no consideration to the experiments themselves. The breeders discard what they consider as 


\section{Horse-Breeding Methods}

worthless and preserve what they consider as best, and a comparison between this selection by the breeders and what happened to the ancestors of these animals from two to four generations previously shows what kinds of experiments are successful and what kinds are failures. The lapse of time between the beginning of the experiments and the selection of the results is so great that the men who do the selecting lose sight of what the other men did at the beginning.

Breeding trotters is probably the most uncertain of businesses. The gambler is certain, sooner or later, to win or lose according to the side of the table he is on. There is a margin for or against him. In breeding trotters, all is chance. In one year a young man bred two cheap mares to two cheap stallions and drew two capital prizes. He was extolled for knowledge of breeding principles, yet in twenty years of subsequent experiments he did not even obtain an ordinary prize. During the same twenty years men all around him were drawing prizes of all 


\section{Dynamic Evolution}

kinds. This is an actual case which shows that the man knew nothing of breeding principles, and that his original success was simply a lucky strike.

In many respects the breeding of trotters is the most remarkable business in the world. In the breeding of other animals there are certain strains noted for their excellence, and these strains maintain their popularity with breeders indefinitely through the years. Not so with trotters. No man knows to-day what family of trotters will be pre-eminent to-morrow. Nearly every year sees some extraordinary trotter arise from a wholly unexpected source, and frcquently from some branch which never before produced anything above mediocre ability. Popular fancy follow's the blood lines of the new phenomena, and breeders keep pace with the popular fancy by continually discarding what they before selected, and selecting what they before discarded. This striking contrast between the results of breeding trotters and the results of breeding other animals is 


\section{Horse-Breeding Methods 7 I}

undoubtedly due to the extreme variability in the manner in which trotters are treated before being bred, as compared to the uniformity of the treatment employed in the breeding of other animals. It is much more reasonable to look for cause and effect in these two things than it is to expect that nature is capricious in the production of trotters, but not in the production of cows or hens.

Hambletonian Io was the great founder of the American trotting stocl. His sire was Abdallah I. Soon after Hambletonian was born, Abdallah was turned out in the wintry blasts on a sandy beach and permitted to starve to death. A few years later the country was scoured for Abdallah blood, most of it being found doing common drudgery.

Hambletonian had one hundred and fifty sons which became sires of standard performers. One of these, known as Alexander's Abdallah, died at the age of twclve, leaving comparatively few offspring. His early life 
was abuse and drudgery. One of his offspring was Goldsmith Maid, for many years the most famous trotter in the world. Within ten years of the time when Goldsmith Maid got her record of $2: 14$, the blood of Alexander's Abdallah was to be found in nearly fifteen hundred registered stallions. Some years later the only prominent descendant in the male line from Alexander's Abdallah was sold to Russia.

At the time of Hambletonian's death, Lakeland Abdallah, Florida, and Knickerbocker were considered among the choicest and most valuable sons of Hambletonian for breeding purposes, and they were bred extensively to the best brood-mares. It rould require a very searching investigation to find a drop of blood of any of these animals in any prominent trotter that existed thirty years later.

Among the other sons of Hambletonian was a horse named George Wilkes which was early sent to the race track because no one would patronize him as a sire. He remained 


\section{Horse-Breeding Methods}

on the track until he was seventeen years of age, and then was sent to Kentucky and bred on shares because no one would pay his stud fees. After he was dead the blood of George Wilkes was more sought after than that of any other horse. Another son was called Artillery. His history is very obscure, but we know that he was sent to the race track because his name is in the list of horses having official records. We also know that he was bred a few times because we find his name in the list of sires. One of his offspring was a son named Bellini which was sent to the race track and later disappeared from sight as far as contemporary breeding gossip is concerned. About the time Bellini died, which was more than sixty years after his grandsire was born, several of his offspring showed astonishing speed on the race track. Every breeder then wanted Bellini blood, but it was extremely rare. A man who secured some of the blood, in a remote section of the country, called Bellini "the greatest stallion ever foaled," yet the total number of 
his progeny was less than one-eighth of that of his grandsire. Similar cases might be multiplied indefinitely. These cases are given simply for the purpose of illustrating the extreme instability of the "blood" of any particular trotting family as compared to the stability of the blood of other kinds of stock. With Holstein-Friesian cattle, the blood of one cow has been predominant since the first importation many years ago.

A horse cannot be in two places at the same time. A stallion on the race track is not in the breeding establishment, and a stallion in a breeding establishment is not on the race track. It is rare that a stallion gets foals in the same year as that in which he is raced.

During the period involved in our investigation, only a small portion of the stallions used for breeding purposes were ever campaigned on the race track. The great majority were neither raced nor trained to race. Perhaps half of them never wore harness. Of those broken to harness, a large proportion were never driven more than enough to 


\section{Horse-Breeding Methods 75}

enable the breeders to observe their "action" and form an estimate of their probable qualities. Those considered valuable for breeding purposes were put in the stud at two or three years of age, while those not considered valuable as breeders were usually sold for racing purposes, or gelded first and sold afterwards. The horses which went to the race track usually had four or five years consumed in training and racing and rarely got into the breeding ranks before six or eight years of age.

Of two horses, one of which went into the stud at the age of two or three, and the other of which went to the race track and reached the stud at the age of seven, which would be likely to have the greater number of foals, and which would be likely to be of the greater average age at the time the foals were born?

There are several things likely to influence the answers to these questions, and these things and the answers are of high importance in understanding the breeding of the trotter 
and the facts which will be given later. First, there is the advantage one horse has over the other in regard to the number of years in the stud. This should ordinarily make the first horse a sire of a much more numerous progeny than the second horse. Second, the considerable number of foals got by the first horse while the second is on the track should make the first a sire at a less average age than the second. Third, the maxim of breeders of "breed to the blood of the winner" and not to the winner should give the first horse an advantage over the second horse in breeding operations after the second horse had retired from the track. This is particularly true of full brothers, or horses closely related to each other in blood. The first horse would ordinarily be patronized more frequently and be provided with the better class of mares. Fourth, the temporary loss of fertility coming from the strain of racing should reduce the actual number of progeny got by the second horse provided his opportunities were equal to those of the first horse. 


\section{Horse-Breeding Methods}

It rould also tend to increase his average age as a sire.

We will come to these things later when we consider the ages at which horses with and horses without race records appear in the pedigrees of 2 : Io trotters, and also when we consider the number of performers sired by two brothers, one of which went to the race track and the other of which did not. Consider two horses, one of which retired from the race track at the age of seven and thereafter spent his life in a box stall, and another horse which was not raced but was driven regularly all his life. At what ages will the two horses be in their best dynamic condition? This will also come up in the pedigrees of 2 : Io trotters when we consider the ages at which these two kinds of horses get their best progeny. The best progeny are those which "breed on," and those which breed on are not always the star performers. Good performance on short distances comes from energy of high potential even when that high potential does not mean a large quantity. 
Those animals breed on which have such a large quantity of energy that only a small per cent. is dissipated through the reproductive process. 


\section{CHAPTER V}

\section{THE $2:$ IO TROTTERS}

High Speed at the Trot an Artificial Gait-The Factors of Work-Percentage of Record-Horses when the 2 : 10 Trotters were Born Compared with Record-Sires of 2 : 10 Trotters-Ages of Non-Record Sires by Sex Relationship-Birth of 2 : Io Stallions Compared with Time when their Sires were Raced-NonRecord Sires Examined-Sires of Mares and Geldings -Unknown Dams-Dams with and without Records -Special Cases-Geldings-Ages of Record and Non-Record Horses in Earlier Generations-The Significance of Tables.

TURNING from general principles to the purpose of testing the theoretical considerations previously set forth, the first thing is to select animals with great stores of energy and examine their pedigrees to see if we can learn how they became possessed with their great accumulations. In doing this we select 2 : Io trotters, remembering, how- 
ever, that the mere fact that a horse is able to trot a mile in $2: 10$ is not, of itself, evidence that he has more energy than his parents or grandparents. Still we may be certain that 2 : Io trotters, as a class, are much superior, in the possession of energy, to their grandparents.

This will be evident from the fact that prior to $188+$ no horse in the world had sufficient energy to carry him at the trot for a mile in $2: 10$, and the grandparents of horses born before 1898 lived in this earlier period. If we carry the pedigrees back five generations, we span the larger part of the nineteenth century and come to a time when there was no such thing as a $2: 30$ trotter. Yet it is from these early animals that our present trotters came, and in a majority of cases we can trace the main lines of descent. In this connection it should be remembered that while trotting is a natural gait for horses, high speed at the trot is an artificial gait requiring an extreme amount of energy, and one entirely developed within the last century. 


\section{The 2:10 Trotters}

We must measure the amount of work performed by the parents of these 2 : Io trotters before they produced these particular animals and then see if the accumulation of energy by these parents was greater than that which horses usually accumulated before being bred. If this examination shows an actual excess accumulation by the parents of these trotters before reproduction, then that fact will point to the accuracy of the theoretical considerations advanced. If they do not show this excess accumulation, then the theory falls to the ground. It will not fall to the ground because some single case may show a lack of accumulation by the parents, because the accumulation may be further back, and the parents may have simply worked enough to preserve and pass along what they received from the grandparents. But it will fall to the ground if any single case can be found in which the calculations for work performed within three or four generations is clearly not enough in total to produce an accumulation which will ac- 
count for the excess energy found in the 2 : Io trotter.

The accumulated energy of parents is measured by the work they performed before reproduction, and that work is measured by two factors - the rate at which work was performed, and the length of time during which such work continued. The first is determined by historical and official records, and the second by the ages of the parents. If both factors are either large or small, the product must be correspondingly large or small, but the size of one factor does not prove the product when the other factor is unknown. It is the product we are after, and while we must look for the product through its factors, any consideration of a factor which does not look ultimately to the product will fail in its object.

At the time this investigation was made there had been 180 animals which had trotted a mile in $2:$ Io or less. These horses were born between $\mathbf{I} 8 \boldsymbol{j}+$ and $\mathbf{I} 898$, with average dates of conception in 1889 for mares 


\section{The 2:10 Trotters}

and geldings, and in 1890 for stallions. In I 876 the number of stallions having records was less than 2 per cent. of registered stallions, while in 1892 the stallions with records were about 9 per cent. of those registered. Considering that at the dates in question stallions which had been to the race track were not patronized as liberally as those which had not, it is probable that not over 5 per cent. of the trotters horn between $\mathbf{1} 874$ and I 898 were by sires with records. Contrast this with the fact that of the 180 animals which trotted in $2: 10$, I2 1 , or 67 per cent., were by sires with records. An animal which obtains a record acquires a good deal of energy by his training and racing, and the difference between 5 per cent. and 67 per cent. is a clear indication that such an acquirement by sires is of advantage in producing 2 : Io trotters.

Taking the other factor of energy as represented by the ages of the sires of these 2 : Io trotters, we find those ages ranging over practically the entire scale of ages at which 
sires reproduce, and averaging the same as they average in ordinary breeding operations. In this we have nothing to indicate any unusual accumulations of energy in the sires before reproducing, but divide these trotters into groups of stallions, mares, and geldings so that we can consider the sires of each individually, and we immediately get indications of an accumulation of energy accompanied by an indication that an accumulation located after sexual maturity is sexual in character and is transmitted in accordance with the laws governing the transmission of secondary sexual characters. The sires of stallions are older than the sires of either mares or geldings. Also, 77 per cent. of the sires of stallions have race records, while only 62 per cent. of the sires of mares and geldings have race records.

The reader will probably jump to the conclusion that the sires with records are the old sires, and that the sires without records are the young sires, and he will probably recall what was previously said about the ages of 


\section{The 2:10 Trotters}

sires when part begin at an early age and part not until after they have retired from the track. The production of 2 : Io trotters reverses the natural order. For stallions, the sires with records are much younger than the sires without records.

\section{Sires of $2: 10$ Stallions}

45 Sires with records.......... average age: 9.8 years 13 Sires without records........ average age: 13.6 years 58 Sires of Stallions............ average age: 10.71 years

A tabulation of 1000 cases, made from the Trotting Register, shows that the ages of sires of horses born between I 823 and I 890 ranged from 3 to 27 years, and that the average age was 10.43 years. The striking thing about the above table is the fact that one group of sires falls below this average while the other group is considerably above it. As age means time, and time is a factor of energy and not of anything else, any variation, other than a mere accidental one, in the average age of a group of sires from the normal average, has reference solely to Hork: performed by those sires bafore reproduction. 


\section{Dynamic Evolution}

Whether the present variation is due to accident or to the operation of a law of nature we may determine by examining the sires in detail and learning what relationship existed between the ages of the different ones and the work they performed.

Examining the 45 sires in detail tre find that they range from 3 to 23 years of age, and when we compare these ages with the years in which these horses were on the race track, we find that they got their 2 : Io sons at dates very close to the dates when they retired from the track. We know that a horse is at his highest dynamic development at the close of his racing career, and that thereafter, in the great majority of cases, he loses energy by idleness. If the energy which a horse acquires by hard work is not transmitted to offspring, then it is very strange indeed that, of the thousands of foals got by these 45 sires, only those sons which were got when the sires were at their highest dynamic development and lowest fertility were able to get into the 2 : 10 class. 


\section{The 2:10 Trotters}

Examining the 13 sires which had no records, we find them ranging from 6 to 23 years of age, and only three cases of a sire less than II years of age. The 6-year-old sire, though not raced to a record, was "worked for speed" shortly before he got his son in the list. The lack of a record is, therefore, a pure technicality. The horse was actually developed by training, and he got no other son of 2 : 10 quality after his development was permitted to decline in the stud.

The other two cases of sires less than I I years of age are two 2 : 10 stallions got by Jay Bird a few months after he obtained a non-standard record of $2: 3 I^{3} \%$. Although Jay Bird lived to be thirty years of age and got nearly a thousand foals, in no other year did he get a son of 2 : Io quality.

If we should eliminate these three cases on the ground that they are in essence the same thing as sires having records, then the average age of the remaining ten sires is about $\mathbf{I}$ years. Of these ten, two sires had been raced 
and had records slower than standard, two trotters were by Electioneer which had been driven from five to seven miles per day for many years before he got these sons, two other trotters were by Pilot Medium which had been similarly driven, and two were by sires in regard to which we have no information.

The detailed examination of the sires of these $5^{8}$ stallions shows that sires must be dynamically developed by work performed before they can get sons of 2 : 10 quality. If the rate of work is rapid, as in special training and racing, the requisite amount of work can be accomplished in a comparatively. short time. But if the work is slower, then more time is required. Also, the fact that the sires which were trained and raced got their sons of 2 : 10 quality principally at times very close to the terminations of their racing careers indicates that a loss of energy due to idleness by the sire can rarely be compensated for by any such fortunate combination of qualities existing in the dam. Breeders 
have never consciously taken their best mares to stallions at the times when they retired from the track and not at other times. The fact that stallions which have raced long and hard are partially sterile at this time has induced them to act in the contrary manner. Breeders do not like to have their mares barren.

There is, for the sires of mares and geldings, no such relationship as that set forth for stallions. It is true that the natural order is also reversed here, by the record-sires heing younger than the no-record-sires, but the difference is not great and the apparent conclusions to be drawn from the fact of difference are not sustained by other facts. As far as the mares are concerned, the difference between 9.8 years and a probable 12 or 13 years for sires with records may be accounted for by the fact that the first progeny of stallions are more frequently trained than later ones, the object being to determine the quality of the horse as a sire. In the case of geldings there is an additional 


\section{Dynamic Evolution}

reason founded upon the belief of breeders that the strain of racing "saps the vitality" of horses and injures their offspring, with the result that the sons of horses sent to the race track are usually gelded until those horses prove their value as sires. As a horse of popular breeding is worth more in the stud than on the track, this does not apply to the same extent to the horses never raced.

\section{Sires of $2: 10$ Mares}

4I Sires with records............ average age: 9.8 years

25 Sires with no records.......... average age: 10.8 years $\overline{66}$ Sires of Mares............ average age: $\overline{\text { Io. } 16}$ years

Sires of $2: 10$ Geldings

35 Sires with records. .........average age: 8.II years 2 I Sires without records.........average age: 10.76 years 56 Sires of Geldings........... average age: 9.11 years

These sires range from 3 to 23 years of age, with no material difference for sires with or without records, or for sires of mares or geldings. Fifteen of the sires without records are six or less years of age, a fact which indicates that the age of the sire has nothing to do 


\section{The 2:10 Trotters}

with the qualities of a mare or a gelding. If energy acquired by work performed after sexual maturity has a sexual quality, then a sire which is old enough to reproduce has acquired all that he can transmit to his daughter or gelded son. If enersy acquired in the youthful stage car be dissipated in an hereditary sense by idleness in the adult stage, then it would seem that mares and geldings of 2 : ro quality would never be begotten by old sires. The evidence indicates energy acquired in the youthful stage continues through the adult stage in the same way that the milking qualities of a cow continues through her son.

Although the percentage of race records for sires of mares and geldings is less than for sires of stallions, it is more than for ordinary sires of trotting stock, a fact which indicates an advantage to mares and geldings to have sires trained for racing purposes. An examination of these sires shows that the majority of them were raced at two and three years of age, which means still earlier training. An 
inquiry into the history of those sires which had no records shows, as far as it shows anything at all, that the majority had some actual training as colts with the prospective intention of sending them to the track. Some of them trotted in races in less than standard time but got no records because they did not head the procession under the wire.

The general facts may be set out in another form by means of the following tables:

Sires with No Records

1 3 Sires of Stallions............ average age: 13.61 years 25 Sires of Mares............. average age: 10.80 years 21 Sires of Geldings........... average age: 10.76 years

Sires with Records

45 Sires of Stallions........... average age: 9.80 years 41 Sires of Mares...............average age: 9.80 years 35 Sires of Geldings............. average age: 8. I y years

With systematized breeding operations and a Trutting Register in which to keep track of trotting stock, it would seem as if there would be no difficulty in obtaining full information about the dams of such animals 


\section{The 2:10 Trotters}

as 2: Io trotters, but as a matter of fact there are 32 cases in which practically no information is to be had. They are known to be of trotting stock by their appearance and actions, but no one knows when they were born or what sires and dams they had. In some cases we know the lines of descent but have no dates. 'This is strongly indicative of rougla usage in many parts of the country and at the hands of many persons. Five of these are dams of $2:$ Io stallions, nine are dams of $2: 10$ mares, and eighteen are dams of 2 : 10 geldings.

At the time these horses made their records and before, it was more common to race mares than to race stallions, but it was not c'mmmon to use for breeding purposes those mares which had been to the race track. As a consequence, dams with records are less numerous than sires with records.

\section{Dams of $2:$ : 0 Stallions}

4 Dams with records......... average age: 11.00 years 49 Dams without record ...... average age: 9.57 years As mares which go to the race track first 
and to the breeding ranks later reproduce at a higher average age than those which go directly into the breeding ranks, we have the normal condition indicating that the age of the dam has nothing to do with the qualities of her sons as performers. The ages of the dams with records are very uniform, but the dams without records range from four to fifteen. A four-year-old dam probably never wore harness, or if so, to only a small extent as a two-year-old. Fillies are often trained at one, two, and three years of age, but such fillies ordinarily go first to the race track. A four-year-old dam (bred at three) cannot possibly have a material amount of dynamic development acquired after sexual maturity, hence, if anything she acquired before she was bred was of advantage to her son it must be that which she acquired in her immature stage.

\section{Dams of 2:10 Mares}

9 Dams with records......... average age: 7.89 years 48 Dams without records....... average age: 10.63 years Here we have a greater number of dams 


\section{The 2:10 Trotters}

and a greater difference in the average ages of the two groups than we found for dams of stallions. It is the reversal of the normal order which we would expect if energy acquired after maturity is transmitted in accordance with the laws governing the transmission of secondary sexual characters, provided these dams without records were animals which worked before they were bred. Generally this is true.

Of the dams without records, one was second in a race where the record was $2: 13 \frac{1}{2}$, two had unofficial records faster than $2: 30$, and six had records slightly slower than standard. The facts then are that 18 of the dams of these $2: 10$ mares were trained and raced and 39 were not raced, as far as the records show. An examination of the brood mare tables of the Trotting Register shows 22 of these non-record dams as not being the dams of anything else than these 2: 10 mares, while in the most of the other cases there are few other offspring. In many cases the dams are not registered in 
the books at all, and are not standard bred. The facts of their pedigrees were learned only after their daughters became famous on the track. This is the case with the dam of Lou Dillon, the one-time fastest trotter in the world. These facts indicate strongly that the dams of the 2 : Io mares were workers and not breeders in the sense that they were selected in their early age to become brood mares because of their known merits.

One of these 2 : 10 mares was out of a threeyear-old dam without a record, and no infurmation as to what happened to that dam in her one-year-old form. This almost certainly represents a loss of energy by the dam which would ordinarily preclude the production of a 2 : Io mare, but the other things involved are unusual. The sire of this 2 : Io mare was extremely developed in his youth and was the champion three-yearold trotter of his day. Back of this threeyear-old dam was an unusual amount of development, the nature of which may be surmised by the fact that she was half-sister 


\section{The 2:10 Trotters}

to the champion full-aged trotter, and aunt of the champion one-year-old trotter. It would require too much space to go into the full details of this case, but it may be said that it does not present much difficulty.

The case which has caused me more trouble and uncertainty than any other is that of the 2 : Io mare Alix, out of a five-year-old dam without a record. If it is possible for energy to get into an animal in any other manner than that set forth in the theoretical discussion, this is the best case I know of to prove that fact. Energy can be traced to her from sire and grandsire trained in their colthood, but the trouble with the case is that there are several comparatively young dams without records close up and no information as to what happened to those dams. The factor time in this case is small without information as to what the other factor may be. Repeated inquiries as to the dam of Alix have yielded only the information that she was nervous and extremely "high-strung." Alix was slender and somewhat frail. She had a "frictionless 
gait" and extreme speed. She died early and, it is believed, without having had a foal.

It may appear that I am wasting time on an individual case, but really it is more important to prove one contradicting case than it is to prove a thousand others. If it can be proved that energy can get into an animal by a simple variation without work being performed to concentrate it, then we must go back and revise general principles. My opinion is that this case is consistent with general principles but that it represents a rare combination which it would require too much space to discuss here. I have, however, discussed it at length in previous contributions. With the suggestion that it is a case needing further investigation, I will leave it as a partial enigma.

\section{Dams of $2: 10$ Geldings}

II Dams with records. . Average age: 9.45 years

27 Dams without recurds. Average age: 9.85 years

These dams range from + to 22 years of age, being substantially the same for those with and without records. Stallions with records 


\section{The 2:10 Trotters}

are bred at an older average age than stallions without records, but that is not necessarily true of mares. Outside of the stud, stallions are rarely used except on the race track, while many mares do not get records to show their road work. The dams of stallions are commonly broou mares from an early age, while the dams of geldings more commonly are road mares.

The average of these dams without records is very close to the average age of all dams in breeding operations and signifies that the work performed by a dam after sexual maturity has no bearing upon the qualities of her gelded son. The low average age of the dams with records, when such dams ordinarily produce their offspring at a higher average age, may be explained by the general practice of gelding the earlier sons and not reserving any sons entire until the dam demonstrates her ability to transmit speed to her offspring. It is a common practice for breeders to train, at their own expense, the first foals of both sires and dams for the purpose of learning 
the value of these sires and dams as breeders. The result is that technical records are more numerous for first foals than for later ones.

The facts given here, and other facts to be found in the pedigrces, indicate that a gelr 1 ing is essentially an immature animal. Ile grows old without becoming mature. There are also indications that the gelding pedigrees will throw light on the problem of neuters among insects, but there is not space here to consider that matter.

In coming to grandparents and carlicr progenitors of 2 : Io trotters we find more definite and precise information than we find in the parents. We also find some now information. Part of this new information relates to the difference between performance and "breeding on," and part to some peculiar things in transmission.

Mention was previously made of the horse George Wilkes which was on the race track longer than any other stallion known to history, and which was bred after retirement. George Willes was not the sire of any 2 : 10 


\section{The 2:10 Trotters}

trotter. He was too early in history for that, but as a grandsire and great-grandsire of extreme speed he outranks all other horses. Stallions which went to the race track, at the time under consideration, usually retired to the stud at about the age of seven, with very few retiring more than two years earlier or later than this age. Creorge Wilkes retired ten years later than this at the age of seventeen. If we should take the average age of all horses with records, that average would represent neither George Wilkes nor the other horses, but would represent the average age as being centered at a point between the two where, in fact, practically nothing exists. Such an average would, of course, be deceptive. To avoid this deception, George Wilkes will be omitted from the averages, and that animal will be considered later by himself.

The details of different generations of male and female ancestors, with illustrative diagrams, have been given in previously published articles. Here these will be condensed into a few tables. 
Average Ages of Male Ancestors of 2 : 10 Stallions

With records

No. Ages
Without records

No. Ages

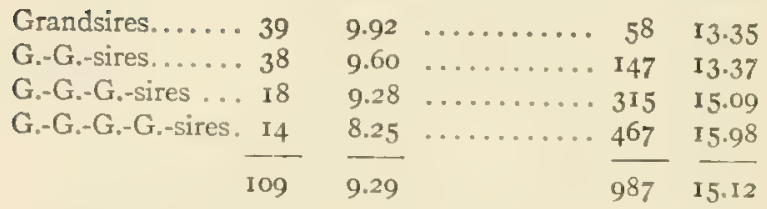

It should not be presumed that the Iog horses with records, and the 987 without records represent that many scparate and distinct animals. Some animals are repeated many times in these 180 pedigrees, and the repetition of the same animal in many pedigrees shows what ones breed on. These animals which are repeated in many pedigrees are brothers and very close relatives of many thousands of other standard registered stallions which do not appear at all. The fact that threc-quarters of all horses are born before their sires are $\mathrm{I}+$ years of age compared with the average ages of the sircs of 987 animals which did breed on to the 2: Io trotters, shows that it is the progeny of young sires which have been principally 


\section{The 2:10 Trotters}

eliminated as unfit. When we go back four generations and find that the only animals which survived the weeding process came from sires averaging nearly sixteen years of age, we cannot but realize that the age of the sire has a bearing upon the quality of the offspring. As age relates only to work, there is no mistaking what the figures mean. When we look at the average ages of sires with records through four generations, we see set before us a means by which the offspring of comparatively young sires can be saved from elimination as unfit. When we stop to think that the I09 sires at an average age of 9.29 years probably produced, at an average age of 12 or I 3 years, some 20,000 or 30,000 other progeny which did not breed on to 2: Io quality, we are forced to believe that there is something particular about the merits of these horses at their earlier ages. When we examine these 109 record horses in detail and the dates when they left the track for the stud, we find that the time which represents their highest dynamic development 
also represents very closcly the time when they produced the offspring most likely to breed on to extreme speed. It is the same thing, extending uniformly through four generations, which we found for the immediate sires of stallions, and when we find such a uniformity extending over nearly forty year's of time, it must have a significance.

And what of the 987 sires without records hich appear in these pedigrees at the average age of fifteen years? When we examine them in detail we find that they represent. only a little over one hundred separate individuals, the whole number being made up principally of repetitions, some horses many times, some horses a few times, and sone horses appearing only once as the sire of sonue remote dam. When we examine the frequently repeated horses we find them to have all been horses which were driven in harness and driven hard. Some were owned by men who drove them for the mere pleasure of driving, some were long in the hands of sports and gamblers of unsavory reputa- 


\section{The 2:10 Trotters}

tion, some of them were in the hands of young men who drove them recklessly about the country in riotous sprees, some were "butchered" in their training, and some were owned by reputable brecders who made it it practice to drive their stallions every day an 1 to occasionally speed them but not enough t's interfere with their stud duties. The number of horses in this list which had their hips knocked dorn or were otherwise injured by reckless driving is surprisingly large.

We will not here go into the details in regard to the male ancestors of mares and of yeldings, and the female ancestors of all three roups, - that has been done in articles previously published,- - but we will close this branch by tables covering all of them.

\section{Male Ancesiors for 5 Generations}

Sires with Records Sires without Records

$$
\text { No, Av. Ages No. Av. Ages }
$$

\begin{tabular}{|c|c|c|}
\hline $5^{8}$ Stallions... . 154 & $9.44 \ldots \ldots \ldots 1000$ & 15.10 \\
\hline 66 Mares.... . I77 & $10.22 \ldots$ & 14.65 \\
\hline Geldings.... 144 & $9.23 \ldots \ldots \ldots 783$ & I3.97 \\
\hline 77 & 9.66 & 4.62 \\
\hline
\end{tabular}




\section{Female Ancestors for 5 Generations}

Dams with Records Dams without Records

No. Av.Ages No. Av. Ages

58 Stallions.... 34

66 Mares...... 42

56 Geldings..... $3^{8}$

II4

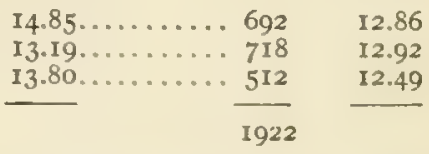

The significance of these tables does not reside in the fact that they include the ages of more than 5000 sires and dams, but in the fact that they cover all of the generations involved in the production of $2:$ Io trotters from an original stock not capable of trotting a mile in three minutes. They tell us that each increase of energy, generation by generation through a century of time, came from animals which did an excessive amount of work before reproducing, and that when any part of a generation failed to perform such work before reproducing, then no corresponding increase of energy was found in the offspring of that part. They also tell us that when work is performed in one generation sufficient to cause an increase of energy in 


\section{The 2:10 Trotters}

the next, and this work is followed by idleness before reproduction, then the progeny coming after this idle period have less energy than those produced before the idle period began.

These are plain facts seen primarily by the ages of the sires and dams included in the table, and secondarily by the relationship existing between these ages and the known work performed. They indicate, as plainly as facts can indicate, what work was performed in connection with each generation to cause the next succeeding one to inherit more energy than its predecessor. The fact that there has been a steadily increasing concentration of energy, generation after generation, indicates that further concentration may be made by further work of the same kind applied in the same way. A limit is no more obvious now than it was when the first $2: 30$ trotter appeared. 


\section{CHAPTER VI}

\section{EFFECTS OF TWO GENERATIONS}

Sex Limited Energy - The Trunsformation of EnergyBrothers as Sires and Promemitura-Decent from Brood SIarce-Amont, Belmunt, Divtator, Kuiunteer, Harde, and Happy Mediun-Grandululiren

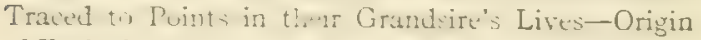
of Early Speed.

IN the earlier tables it was shown that the sires of 2 : 10 mares and 2 : 10 geldings averaged 10.78 years. In the next to the last table it appears that when we take all of the male ancestors for five generations we find that those for mares and geldings average over fourteen ytars. The matter involved can best be set forth by an illustration.

The horse George Wille's appears as grandsire or earlier progenitor Iog times: fo times descent from him is to 2 : 10 stallions, 37 times to 2 : Io mares, and 32 times to 2 : I0 


\section{Effects of $\mathbf{T}$ wo Generations ion}

geldings. The descent is through both sons and daughters, and there are all combinations of descent except one. Descent from George Wilkes to 2: Io stallions is indifferently through sons and daughters, but not so in descent to 2 : io mares or 2 : I0 juldings. The lines of descent through sons to mares and geldings of 2: 10 quality are plentiful, but the blood of George Wilkes reaches these animals through a daughter only when there is another male in the line of descent between the daughter and the mare or gelding. It also reaches these mares and geldings only when the son or daughter's son in the line of descent was trained to some extent during his immature stage, and the frequency with which it occurs in any particular line appear: to be closely proportional to the extent of this early training.

Here we have a horse which did mone trotting work during his adult stage than any other horse, and this work involved an accumulation of enersy in the organs used in trotting. If we assume that this accumu- 
lated energy was sexual in character and was transmitted in accordance with the laws governing the transmission of secondary sexual characters, and also assume that a male descendant (son or grandson) which inherits this accumulation can, by special activity during the immature stage, transform his inheritance into an ordinary or non-sexual character, then we have a complete explanation of the phenomena. The peculiarity pointed out here is not an isolated instance. The same thing can be found, in a less pronounced form, running through every one of the 180 pedigrees which is not too fragmentary to show anything. The 2 : Io trotters are most frequently produced when the adult development of sires of sires is greater than that of sires of dams, and also when that of the dams of dams is greater than that of the dans of sires. Both of these are shown in the pedigrees of stallions, pedigrees of mares, and pedigrees of geldings; by records, by ages, and by amount of trotting work done. Nor are these facts confined to the 2 : Io trotters. 


\section{Effects of $\mathbf{T}$ wo Generations II I}

George Wilkes was much better as a sire of fast stallions than he was as a sire of fast mares or fast geldings, but those sons of his which were considerably trained in their immature stage and not much in their adult stage were better as sires of fast mares and geldings than of fast stallions. The same thing is generally true of all stallions which were considerably developed by trotting work when adult and whose sons were developed in their colthood. The uniformity and generality of these facts are impressive, and there appears to be no explanation other than that given.

The horses George Wilkes, Robert McGregor, Woodford Mambrino, and several other stallions were raced extensively after becoming mature, and they acquired a good deal of energy by this work. These horses sired quite a number of daughters, and these daughters had produced 357 standard performers up to the time this investigation was made. About one-third of all performers are stallions and about two-thirds are mares and 
geldings. From what has been said before the reader will probably be able to tell in advance what the Trotting Register will say about the sexual distribution of the performers produced by these daughters. The book shows, not one-third and two-thirds, but 179 stallions and 178 mares and geldings. From similar facts for many horses similar predictions may be made in regard to what the books will say about the descendants two or three generations after the described horse.

It has been pointed out before that the horse which goes to the race track does not get as numerous an offspring as the horse which goes immediately to the stud. Also, that the horse which is raced is better developed dynamically than the horse which stays at home. There are exceptions when the stay-at-home is worked hard in harness, and the raced horse is idle for years after a viry short racing carecr, but on the average the raced hors is better developed than the one nut raced. There are a good many cases 


\section{Effects of Two Generations II 3}

of stallions which were full brothers, one of which went to the track, and the other of which did not. A comparison between these full brothers is instructive. Inown cases are given in condensed form, the details, including the names of the brothers and those of their sires and dams, having been previously published in The IIorse World of December 17, 1912.

\section{Performers Sired by Full Brothers}

88 Brothers with records.....2963.........Average, 33.I 96 Brothers without records. . $963 \ldots \ldots$.... Average, Io. Lust by not Training 96 Brothers........2215 performers

\section{Performers by Sons of Full Brothers}

Suns of $\varepsilon 8$ with records...... $4380 \ldots . . \ldots$. Average, 49.2 Suns of 96 without records.... J $292 \ldots . . . .$. . Average, 13.4 Additional loss through Sons............3+3I performers

These two tables are pronounced in showing the advantage in training and racing a horse before he is bred, yet they do not tell all of the truth. A few of the 96 brothers which sired 963 performers, were actually trained though not raced, and these few are the best of the 96. The sons of the 96 num- 
ber several hundred, but the larger part of the $\mathbf{I} 292$ performers were got by those particular sons which were raced. Thus, of the several hundred, fifteen which went to the track and were raced sired more than onethird of the entire 1292.

We can get a little more light on this by taking the record sons of record brothers, and the non-record sons of non-record brothers.

\section{Two Generations with and without Records Performers Produced}

By record Sons of 27 record Bruthers. . 685. Average, 25.3 By non-record Sons of 28 non-record

Brothers............... 50..Average, 1.8

Performers by Half-Brothers from Same Dams

22 record Half-Brothers......... 666. Average, 30. 25 non-record IIalf-Brothers........ Ioo.. Average, 4 .

Performers by Half-Brothers Ifaring Same Sires

747 Half-Brothers with records... . 6941 . Average, 9.29 1262 Half-Brothers without records. 634I . Average, 5.02

An investigation was made of the effect of two generations of brood mares not required to do work other than produce foals. To do this Volume VI. of the Trotting Register 


\section{Effects of Two Generations II5}

was taken and from it was made a list of all of the brood mares credited with producing five or more foals. These mares were by such sires as Hambletonian, Mambrino Chief, Alexander's Abdallah, George M. Patchen, and other early horses which are the foundation stock of our 2 : Io trotters. They had their foals by such horses as George Wilkes, Electioneer, Nutwood, Almont, Belmont, Dictator, etc., all of which appear repeatedly in the pedigrees of $2:$ io trotters, and all of which were actually among the best sires of their day. Owing to the fact that only a comparatively small proportion of the brood mares registered have lists of their foals given, the ones which do have such lists must be considered to have been the best and most valuable brood mares then living.

These choice mares had 7 I 7 foals by the best sires of the breed, of which probably $35^{\circ}$ to 360 were daughters used principally for breeding purposes. Nearly one thousand separate and distinct animals appear in the pedigrees of our 2 : Io trotters, about seven 


\section{II6 Dynamic Evolution}

hundred of which are dams. How many of these three hundred and fifty odd daughters of the best sires and choicest brood mares should appear among this seven hundred in the pedigrees of the 2 : Io trotters? Three of them are found, each once in the pedigree of a 2: 10 stallion, and one is the grand dam of a 2 : ro gelding. Not one is to be found in the pedigree of any 2 : Io mare. And even these cases are not really cases of two generations of ordinary idle brood mares, unless the last may possibly be such. One is the daughter of a former old road mare, while the other two were trained as yearlings.

Other mares of the same blood, which lived at the same time as these choice selected brood mares and their daughters, appear many times in the pedigrees of $2:$ Io trotters, but these other mares were not brood mares in the ordinary sense. $A$ few were mares sold to drivers for racing purposes, but the great majority of them were animals disposed of at the annual clearance sales to men who used them for drawing 
carriages, busses, delivery wagons, and doing general work, and which later were bred once or a few times to convenient stallions. Such facts make it abundantly clear that two generations of idleness in the same sex are fatal to the production of $2: 10$ speed.

The horse Almont was a famous sire in his day, and he is far enough back in history fur us to get a good perspective of him and his descendants. His fame rested partly on nerit, partly on relationship and partly on slillful advertising. The books show that rearly two hundred of his sons were used for breeding purposes. Of these, about ten per cent. were raced, the other ninety per cent. being considered too valuable to be sent to the track. As sires, the sons which were raced outranked the unraced sons more than sixteen to one. The jresent object, however, is to examine the individual history of Almont and compare that history with the quality of his offspring yot at different times in his life, that quality being determined by 
the ability of these offspring to transmit energy.

Almont was foaled in 1864 and died in I884. He was trained while young and got an official record of $2: 39^{3} \%$ as a four-yearold and an unofficial record of $2: 32$ as a five-year-old. From the age of five to the age of ten he was owned by a man who drove him moderately but regularly, and from the time he was ten to his death at the age of twenty he was owned by a man who did not drive him, or any of his other stallions used for breeding. Almont's relative gain and loss of energy during different periods of time can be estimated from these facts.

Omitting the sons with records, and considering only the ninety per cent. which had no records but were used extensively for breeding purposes, there were six sons which somewhat exceeded the others as sires, though no one of them sired more than fifteen performers. These six are concentrated in the stud services of the sire from the age of four to the age of thirteen.' A more 


\section{Effects of Two Generations II9}

extended tabulation, which included all of his sons that sired five or more performers, located Almont as being at his best at the age of ten. There is descent from Almont to the 2 : Io trotters through several of his daughters, and a similar investigation again located Almont at his best at ten years of age. IWhat Almont sired after he had been idle for two years in the stud was much inferior, and is now practically eliminated from the best stock.

This case of Almont is typical of all cases of horses which had similar histories. Thus, Belmont lived 25 years, the first part containing some training and driving and the latter part being principally idleness. His best sons are compressed within eleven years of his life, and the two sons which overshadow all others are located within two years. This center marks the change from work to idleness by Belmont.

Dictator was foaled in 1863 and lived to be thirty years of age. "He was worked considerably at Mr. Durkee's farm" until the 
end of 1875 , but not thereafter because of the fame of a gelded son,- the first 2 : ro trotter. The only sons of his which amounted to much as sires were from stud services in I 876 .

Volunteer was foaled in 1854 and lived for thirty years. He was driven abusively on the road and was bred so rarely that at the age of ten he had sired only eighteen foals. In 1872 , when he was eighteen years old, it was discovered that he was of more value in the stud than on the road, and thereafter he was liberally patronized by the best mares and got a numerous progeny. The only unraced sons of his which amounted to anything as sires came from stud services in 1872 and 1873 .

Harold lived 29 years. In early life he was used as an all-round drudge and a teaser for other stallions. It is said that he got the champion Maud S. as the result of jumping the fence. When Maud S. showed speed on the track, Harold was relieved from drudgery and put in the stud. The nine sons of his 
Effects of Two Generations I2I

which were superior to all others as sires were got in the next eight years.

Happy Medium was foaled in $\mathbf{I} 863$ and lived twenty-five years. He was in one race at the age of five and in two races at the age of six. At the age of sixteen he was sold to the man who owned Almont and who never drove stallions. The important sons of Happy Medium were got within the space of six years, the center point of which is the date of transfer from one owner to the other.

Without multiplying cases of the same kind let us see what those cited really mean. Collectively these six horses had several thousands of offspring and several tens of thousands of grandchildren. Considering those grandchildren from the standpoint of energy, more than three thousand of them became standard performers, some of them being $2:$ Io trotters. Three thousand performers are a good many, and they all belong to the six cases cited. About one-hall of these three thousand performers, and practically all of the highest quality, came from less than one 
hundred sons and about the same number of daughters; while the remaining and less valuable half came from about 700 sons and the same number of daughters. Now, when we take these sons and daughters which were the best in the production of performers, we find that they (the sons and daughters) were produced in small fractions of their sircs' lives, and that these fractions represent the particular times in life when the sires were in their best dynamic derelopment. Briefly, we have traced the energy conditions of six sires through two generations to three thousand grandchildren, and have shown that the inherited energy found in the grandchildren represents and corresponds to the energy conditions in the grandsires at the points in their lives where the lines of descent begin. Outside blond in two generations, and intervening work, influence individual cases, some of them widely, but in large masses like these the grandchildren accurately represent their grandsires.

These facts may appear so extraordinary 


\section{Effects of Two Generations 123}

as to be unbelievable, but they are easily verified. Volume XVIII. of the Year Book gives these horses with the names of their sons and the number of performers got by each son. From the Index of the Trotting Register it can be determined just when each horse and each son were born. Horse histories by Wallace, Parlin, Busby, and others will tell what happened to the six horses and when it happened. The Year Book also gives the names of the sons and daughters which were raced so that accumulations of energy in the intervening generation may be taken into consideration.

Prior to I 860 it was only rarely that horses trotted in public before the age of six years, and famous trotters did not arrive at their best until sometime between the ages of twelve and fifteen. Goldsmith Maid got her best record at the age of seventeen in 1874 . Now we have horses which trot in $2:$ Io at the ages of two and three years, and few remain on the track beyond the ages of six or eight. A description of the early events 
which led to the production of families of early speed is instructive.

The first time a four-year-old trotted in public was in 1863 . In 1860 the four-yearold stallion Ericsson was driven a mile in $2: 30^{\mathrm{I} / 2}$, and Hiram Woodruff, the most famous driver of his time, called it "an astonishing thing."

During the 70's a large breeder of trotters, Mr. Welch, owned a pacing son of Hambletonian known as Strathmore. This horse was so despised by Mr. Welch that he was not shown to visitors at the farm except on special request. During the years Mr. Welch owned him he was used for drudgery and got only three foals. One of these was a colt called Santa Claus and out of a mare owned by a neighboring farmer. This mare was a granddaughter of the Ericsson before mentioned. Santa Claus was such a poor specimen that Mr. Welch offered his owner another and free serviete of Strathmore if he would only kill the colt. The offer was declined and the colt was trained and raced as a three-year-old. 


\section{Effects of Two Generations 125}

An experiment pure and simple, and one with no precedent.

After Santa Claus had been campaigned on the track for several years he was bred to Sweetness, $2: 2 \mathrm{I} \mathrm{I}_{2}^{\prime}$, a daughter of a horse which had been banged about the country for many years before it was discovered that he was good for anything as a sirc. The product was a colt called Sidney. The owner of Sweetness and Sidney had freak notions about driving youngsters and had no considerations for the feelings of his horses. Tender mercy was not a part of his constitution. "The methods pursued in developing this promising trotter were so drastic that instead of maturing into a trotter of merit, he adopted the pacing gait, shifting to that way of going of his own volition. In his yearling form sidney trotted a quarter of a mile in thirty-seven seconds."

Sidney is the founder of an important family of trotters noted for early specd.

About $\mathbf{1 8 6 3}$ or $\mathbf{1} 864$ a filly, afterwards known as Green Mountain Maid, was put 
through a process of training subsequently designated as the "kindergarten school." This is probably the earliest known case of a filly being trained in this way at an extremely early age.

In I 869 a man who owned a two-year-old colt and a one-year-old filly put them in the hands of a Chinaman to have them worlied at fast trotting, which work cxtended over two or three years. The owner, speaking afterwards, said: "My horses were not trained, they were butchered." An authority on horse pedigrees and horse history said of this young mare: "She was broken as a yearling by a Chinaman and worked as a tro- and three-ycar-old, when her butchery was completed. Her so called training was one long battle in which the swift and puregaited but high-spirited little filly fought to the last gasp." When the process was completed the butchered mare was bred to the butchered stallion and the product was Beautiful Bells, first trained and raced, and later the most famous of matrons. 


\section{Effects of Two Generations 127}

Early in the 70's Dr. Herr of Kentucky made the first systematic attempt to train colts as young as two and three years of age, but he soon abandoned it because of adverse criticism. About ten years later Leland Stanford in California established a "Kindergarten school" for colts and commenced training them in this school as early as nine months of age. At the head of the stud, Stanford placed an early trained horse known as Electioneer, a son of the Green Mountain Maid before mentioned. Practically all of the progeny of Elcctioneer went through this school, with the result that the Electioneer family is now the principal family for early speed. But the most famous part of this early speed comes from the early trained sons and daughters of Electioneer and Beautiful Bells. Other parts of it come through some of those animals with which Dr. Herr experimented at about the time Beautiful Bells was born.

Other families of early speed have since arisen but each time it was by the same 
process. Development was forced on very young animals by drastic methods for two or three generations, after which animals are born with a natural aptitude for early speed. High speed at the trot is an artificial gait forced on horses during the nineteenth century, and high speed at an early age is a second artificial product piled upon the first during the last quarter of the century.

It may seem strange to the reader that these facts could exist for a long time in horsebreeding operations and the breeders not become aware of them. Apart from the fact that breeders have not known what the factors of energy were and how they should be applied in its measurement, there are many things tending to conceal the process involved. First, horse generations are comparatively long and few breeders have remained professionally in the business long enough to see which parts of the product coming from two generations produce the best results. Small breeders do not keep track of long-time results, and large breeders 


\section{Effects of Two Generations I 29}

begin by selecting stock in accordance with what current opinion indicates as the best "blood."

Second, blood is commonly considered through the sires, while the performers have been principally geldings, and mares which have never been bred. When stallions were raced their devclopment came almost exclusively in their adult stage with the consequence that it was sexual in character and had no effect upon the racing qualities of daughters and gelded sons. Mares and geldings of superior quality came indifferently from old sires and young sires, and from sires which had been raced and sires which had not been raced. The sexual character of energy acquired after sexual maturity is a most effectual screen for concealing the facts, and the existance of this screen was not suspected. No one brought the facts together.

With the advent of early training and early speed this screen was automatically removed without its presence being detected, and at the same time horse generations were 


\section{30 Dynamic Evolution}

somewhat shortened as far as the immediate production of early speed was concerned. Under these conditions breeders could see further, and there is now a growing sentiment toward the use of highly developed sires and dams for breeding purposes. They recognize the fact that those horses which have records are better as sires and dams than those which have none. What the breeders do not yet see, however, is that development is lost by idleness, and that development may be accuired in other ways than by racing on the ricetrack. The technical race record is still considered the sole measurement of development. 


\section{CHAPTER VII}

\section{ENGLISH SETTERS}

Laverack's Breeding Operations--Ordinary BreclingChampion Dogs-The Sex-Relationship-Engli.h Setters in America.

IN 1825 Edward Laverack of England bought a brace of setters, Ponto and Moll, a dog and a bitch. Forty years later he had the best setters in the world. Writers, commenting on these dogs, have credited Laverack with being the greatest breeder who ever lived. How did he do it? How did Laverack get the best setters in the world from a stray pair he purchased from a neighbor?

When he was old Laverack published a small book on his sctters, and contemporary literature gives certain other information. When these are carefully analyzed it is found 
that Laverack mas not a breeder at all. He Tas a professional hunter, and a very strenuous one. He used his original brace of setters for hunting purposes, and when they were old he bred them to get more. This second generation was used for hunting purposes until they were old, when he bred brother and sister together to get a third generation. After this generation was old he bred brother and sister to get a fourth, and so on. On one occasion he varied the proceeding by breeding a dog back to his own double granddam, but otherwisc it was brother and sister bred together. During this forty years he never bought dogs, never sold dogs, never had many dogs, and the final generation had no blood other than that coming from the original Ponto and Moll.

1 prominent writer on breeding subjects, Arnold Burgess, in commenting on Larerack's dogs and Laverack's book, gave it as his opinion that the pedigrees in the book were fraudulent. He based his opinion on the improbability of any one using such an 


\section{English Setters}

extreme amount of inbreeding, and the fact that the pedigrees showed from six to nine years between generations. He admitted that it was possible to brced setters with that amount of time between generations, but said that the improbability of any one doing so was so great that he did not believe Laverack's statements. "Stonehenge" also said that while such breeding was not impossible it was "highly improbable." Others, who knew Laverack personally, have credited him with truthfulness.

Another breeder, Llewellin, who made it a practice to run his setters in competitive trials, bought Laverack's dogs about 1870. A few years later six dogs, by Llewellin's dogs and out of Laverack's bitches, were imported into the United States and formed the foundation of what is now known as the English setter in this country. What is given hereinafter is a condensation of the results obtained from an investigation made in 1904 of the progenitors of the then six most recent champion dugs descended from those imported. 
Dogs imported for breeding purposes, and their immediate progeny, are naturally kept busy in the breeding liennels, and only a few of the progeny are trained and sent to run in field competitions for the purpose of keeping the pulplic informed of the qualities of this kind of dog. Training and running dogs consume time and money, and also interfere with their breeding activities. Dogs are bred at from one to eight or ten years of age, with an average of about three or four, but the lines of descent from the original imported stock to the six chamion dogs is not through animals produced by such young parents, nor throush those which were kept exclusively in the liennels for breeding purposes. They are through the dogs which were trained and ran for prizes in field trials, and the average time between generations is over six years, being substantially the same as that which led Burgess to consider the Laverack pedigrees as fraudulent. One line has three generations in twenty-four years, an average of cisht years per generation; 


\section{English Setters}

another line has four generations in twentynine years, an average of seren and onequarter years; and still another line has five generations in thirty-seven years, an average of seven and two-fifth years.

Of all the dogs in these six pedigrees, there is only one young sire, and that one was trained for field trials at a very early age. As there are some eighty or ninety dogs, and an equal number of bitches, in these pedigrees, and as dogs are bred much more when young than when old, it is very reasonable to enquire why none of the early progeny of these dogs appear in the pedigrees of champions. Also, what became of the progeny of those stud dogs which were in the kennels while their relatives were in the ficld? It may be that the dogs sent to the field trials were the best dogs, but how about the breeder who, when blood is scarce and prices are high, will breed his best dogs only sparingly?

Whatever else may be said about the breeding of champion dogs for field work as distinguished from champions in the hench 


\section{I.5) Drnamic Evolution}

show, such champions have come from dogs which did a large amount of field work before they were bred. And the pedigrees of these champions show the same sexual relationship to mork performed that is found in horses. Thus, Gladstone was the first imported dog. and he was considered as the best setter of his day. All of his sons, with one exception. were kept for breeding purposes without being trained. Gladstone appears eighteen times in the pedigtees of these sis champions, seventeen times through his daughters, and once through that son which was trained. What became of the male lines of descent through all of the nther sons of Gladstone?

Each year there are many dogs which are winners in field trials without becoming champions. At my suggestion, the editor of The American Field made a table showing the sex of the winning progeny of eight highly developed dogs which he himself selected because of his knowledge of what occurred in field trials in all parts of the Lnited States. His tahle showed ing winning sons and a 
small number of winning daughters, - the actual number of winning daughters not being recorded and the original data being lost.

Going bart: to the dogs bred betreen 1825 and 1870 , it w11 be remembered that Larerack uniformi-j bred brother and sister together when they were old, except on one cccasion which in rolved breeding a dog back to his granddam. To get that combination, Laverarl: depatted from his usual practice and used two generations of young sires which had no critresponding young dams, and the final anımals which he had came from that combination. The result was inevitabli. In I870 Laverack's bitches were much superior to his dogs, and the best English setters for field work came from crossing Ilewellin's dogs on Laverack's bitches, and not from the reciprocal cross. The marked difference hetween these two crosses attracted much attention among dog breeder.. but the explanation has not before been given. The cross between Laverack's dos: and Llewellin's bitches, however, produced 
many bench show winners, but this involves the structural form of matter and not energy.

It is common lnowledge that setters which win prizes at the bench show are not good as field dogs, and that winners in the field trials are rarely successful at the bench show. Yet both kinds of dogs are of identical blood and came from the same progenitors a few generations previously. The explanation is to be found in selection. When a breeder finds an unusually handsome dog in a litter, one which has the "points" of a setter in their most desirable combination, that dog is considered valuable and is kept for breeding. The other and less desirable dogs of the same litter are sold to men who use them for hunting purposes. A few generations later the descendants of the first dog win on the bench and the descendants of the second dog win in the field. There appears to be no essential reason why a dog having the best points, as observed and judged by cxperts, should not win in the field, except that which 


\section{Engilish Setters}

involves the acquirement and inheritance of energy.

In the pedigrees of horses it was found that the sires in the best pedigrees appeared at greater and greater average ages as we went back, generation after generation, from the 2 : io trotters. This is the result of a postmortem selection coming from finding that the progeny from the offspring of young sires is inferior to the progeny coming from the offspring of old sires. To make it possible to thus eliminate the offspring of young sires there must be a sufficient supply of such offspring so that those remaining after the elimination can furnish all the horses needed in the country. Horses have been bred in America from the earliest colonial days, and at the beginning of the nineteenth century there were thousands of trotters scattered through all parts of the country. In 1907 it was found that of the 22,238 horses which had trotted a mile in $2: 30$ or less, all traced in tail-male to one or another of seventeen foundation horses which lived in the early 
part of the nineteenth century. The only possible exception to this statement must be looked for in the cases of a few horses whose breeding is not given. The remaining untold thousands, once considered important, have been eliminated gradually from what i: known as the trotting stock.

With the English setters in America no such elimination has been possible. The original importations, about 1880 , were of six dogs and a few bitches, and all setters of the present day must trace to these because there are no others to which they can tract. The ages of sires in the earlier generations of the champion dogs must be the ages of the sires of the imported dogs, and the ages of $1 \mathrm{l}^{*}$ inported dogs when they got their progeny. As there were only a few of these setters in this country about 1800 , and as every dogr of the present day has a good many dogs in his pedigree when one goes back four generations, it follows that every dog of the present day must have some young sires among hi: eurlier progenitors. It follow's from this that 
if there is to be any elimination of the progeny of young sires bccause of their inferiority, that elimination must occur, for English setters, principally in the later generations.

This is precisely what the pedigrees of the cliampion dogs show. The sires of champion., averaged 8 years of age when the champirm.: were 1)orn; the grandsires averaged 6.7 .5 years when the sires and dams were bom; the great-grandsires averaged 5.32 years. These ages, and the facts involved, make it perfectly clear that in producing animals of champion character, the progeny of young: sires are relentlessly eliminated whenever such climination is possible. As the ages of sires mean time between generations, and time is a factor in the measurement of energy, the elimination of animals having short time and the preservation of animals having long time clearly point to the inheritance of the cnergy acquired by the sire in the time involved. That there may be no mistake as to the significance of this factor, it is only necessary to point to the fact that, in every case 


\section{It2 Dynamic Evolution}

involving the production of great dynamic development, the other factor-activityneeded for the complete measurement of energy is always of large magnitude. 


\title{
CHAPTER VIII
}

\author{
HOLSTEIN-FRIESIANS
}

Advanced Registry-Milk Production and Percentage of Fat-Cows Selected-Calves at Different Ages of Cows-Bulls-Time between Successive Births.

IN 1906 an investigation was made into milk production by Holstein-Friesian cows. These cows were selected because their milk production is very great, but as they are classified in the register by the amount of butter fat produced and not by the amount of milk, it was necessary to go through the books in detail to find those which were remarkable for milk production. To explain why this is necessary we must go back to the manner in which energy is acquired by work performed, and to the relationship of this manner to the system used in admitting cows to the Advanced Registry. 
The expenditure of energy through an organ causes a concentration of energy in that organ through which it is expended. In cows we have such a concentration resulting from the expenditure of energy in the production of milk, and the amount of the concentration is, within limits, proportional to the length of time during which the expenditure is continued. Thus, a cow produces a greater quantity of milk when she has her second calf than when she had her first, more when she has her third calf than when she had her second, and so on up to her eighth or tenth calf. The exact stopping point is uncertain and probably varies with different cows.

Early in the history of Holstein-Friesian cattle in the United States there was established an Adranced Registry for the recording of those animals which had exceptional merit in the production of large quantities of butter lat. The standard for this was, of course, made so high that only a comparatively small proportion of the whole stock recorded in the herd books cuuld get into the 


\section{Holstein-Friesians}

Advanced Registry. Admission to the Advanced Registry is by official tests for the quantity of butter fat produced in seven days.

The amount of butter fat produced by a cow depends upon two factors, one of which is the quantity of milk produced, and the other of which is the percentage of fat in the milk. Of these, the percentage of fat is more highly variable than the quantity of milk and is the more important factor in determining a cow's admission to the Advanced Registry. Fat is only one of the several solids in mill, and the percentage of fat in the milk of a cow is not affected in any way by the amount of energy she has expended in producing mill. As a consequence, the age of the cow, or the age of her dam, has nothing to do with the amount of fat she produces, except as the amount of fat is influenced by the amount of milk.

It may appear that if the amount of fat is influenced by the amount of milk, and the amount of milk is influenced by the ages of the cow's dem and earlier female progenitors, 


\section{I46 Dynamic Evolution}

then there should be a general relationship between the amount of butter fat produced and the ages of the dams. The answer to that supposition is twofold. First, a general relationship, if established in a mass, would have small scientific standing as against a series of individual measurements accurately made and tested. Second, we are forced to go to the Advanced Registry for official records, and admission to the Advanced Registry is on such a basis that an attempt to show a relationship through butter fat would, in many cases, indicate the facts to be directly contrary to what they actually are. To illustrate this last, let us assume two cows in the Advanced Registry, each producing milk having 13 per cent. of solids, - an ordinary amount. One cow produces, in a week, 400 pounds of milk having 6 per cent. of fat and 7 per cent. of proteids and sugar, and the other cow produces 600 pounds of milk having 3 per cent. of fat and 10 per cent. of proteids and sugar. The first cow producing 24 pounds of butter fat in a week would stand 
ahead of the second corr producing i 8 pounds in the same time, yet the second cow would be expending 50 per cent. more energy than the first cow. Admission to the Advanced Registry is so arranged as to facilitate the production of cases like this, and as there is no means of knowing how many there are of them, any comparison between the amount of butter fat produced by different cows and the ages of their dams would be wholly uncertain.

In examining setters we found that the fact of recent importation made it impossible to find four generations of old sires because, before we reached that far back in pedigrees, we found a time when there were not enough animals in existence in the country to complete a pedigree without including the offspring of young sires. The same thing existed, in a more pronounced way, in Holstein-Friesian cattle at the time the investigation was made in $\mathbf{1 9 0 6 . ~ T h e ~ f o u n d a t i o n ~ s t o c k ~ o f ~ t h e s e ~ a n i - ~}$ mals was imported shortly before 1890 , and there was not time enough for the existence 
of three generations of old dams in this country. To learn what effect one year more or less from time of importation to time of investigation would have on the age of dams, the cows selected were divided into groups, one group consisting of cows born in rgor, a second group consisting of cows born in I902, and a third group consisting of cows born in 1903. The results will be given later.

The time of importation limited these pedigrces to three generations, and even some of these were fragmentary. All of the cows which were born in the years indicated and which were officially tested up to February I 5,1907 , were gone over in detail and from them were piclied out I +4 which produced more pounds of milk in seven days than any others recorded. A stop was made at this point because these cows had in their pedigrees just Iooo dams.

Holstein-Friesian cows usually first come fresh at the age of two years, and then regularly each year thereafter. When cows are bred in this way and increase normally in 


\section{Molstein-Friesians}

numbers, as these cows did in the years immediately following their importation, a theoretical table shows that 28.6 per crit. of all births are first calves, 20.9 per cent. are serond calves, I 5.8 per cent. are third calves, I I.5 per cent. are fourth calves, and the remainder are fifth and later calves. A tabulation, however, shows that the deaths of older cows slightly increases the percentage of earlier births and decreases the percentage of later ones. This tabulation gives 5 I per cent. of first and second calves, 25 per cent. of third and fourth call's, and $2+$ percent. of fifth amel Iater calves.

On this basis, 510 of the 1000 dams in these pedigrees should have been with either the ir first or second calves, and 240 should have been with their fifth or later calves, provided, of course, that the dynamic development a cow acquires by producing milk is not transmit ted to her later offspring. As a matter of fact these pedigrees slowed no such number of first and second calves. They showed that 238 first and second calves had been climinated, and 
that the same number had been added to the fifth and later calves. Throughout its entire length the table showed the discrimination to be uniformly against the earlier births and in favor of the later ones.

First and second calres constitute fifty-one per cent. of all calves in normally increasing stock. In the group of cows born in I90I, 32.7 per cent. of the dams in their pedigrees were found to be dams with their first and sciond calves. In the group of cows born in $I ; 02$, the first and second calves in the pedisrees were reduced to 28.5 per cent., while in the group born in 1903 they were further reduced to 22.I per cent. The elimination of carlier progeny goes on rapidly when there is selection for functional superiority and there is any opportunity for such elimination.

This weeding out process, by which the progeny of young dams is eliminated to improve the stock, occurs most rapidly when there are surplus animals to be disposed of, and, as there are more surplus bulls than there are surplus heifers, it should occur 
principally among the bulls. This may be seen by comparing the average ages of their dams and the average age of other dams. By tabulation it was found that during the years just before the investigation was made, these cows came fresh at an average age of 4 years, 3 months, 2 I days. The Iooo dams in these pedigrees were 33 per cent. greater age, that is, 5 years, 8 months, 18 days. The dams of all of the bulls averaged 6 years, 3 months, 7 days, while the dams of the paternal grandsires (the point where there is the greatest possible selection and consequent elimination) averaged 7 years, 5 months, 5 days. This last average is over 70 per cent. above the average breeding age of Holstein-Friesian cows, and is the highest average found at any point in the pedigrees.

Certain bulls have become famous because of their ability to sire daughters producing a large amount of butter fat and consequently able to enter the Advanced Registry. As a general thing these famous sires appear with great frequency in the pedigrees of the 144 
coms producing the greatest amount of milk, but the third most eminent sire does not appear at an: place in any pedigree. An inspection of the corrs sired by this bull shors that ther are noted for small quanrities of mill containing hish percentages of butter fat. An inspection of the pedigree of this bull shows that he was his dam's first calf. While a similar inspertion of the pedigrees of all of the other famous bulls shows that not one of them is any earlier product than lis dam's fourth calf. It is clear from this case alone that the manner in which the total olids in milk are dirided into fat. proteids, and sugar is in no way influenced by the age of the dam.

The best of the Holstein-Friesian stock in America is descended, in one line or another, from a cow knnwn as DeKol 2d. This cow lived long chough to have at least eleven calres. What hecime of her early proseny and their descendants does not appear, but after she was eight years of age she became the dan of five bulls which herame very 
important sires. Ordinarily cows produre calves twelve months apart. Here there happen to be two cases in which De Kol $2 \mathrm{~d}$ had calves thirteen months apart, and one case in which they mere eleren months apart. The tro sons which De rol ad had thirteen months aftet her previous calves are nearly equal in merit and far above any of her other sons. The one son which she had eleven months after her prexious calf was inferior to any of the othets. This matter has not. been examined sufficiently for any conclusions to be drawn, but it appears to indicate that a dam may have her energy exhausted by prcducing offspring too close together, and that an offspring born an unusually short period after the next preceding one will suffer because of that exhaustion. It would also appear as if the result was due to partial starvation during the period of gestation.

In the pedigrees of the $2: 10$ trotters it was found. when successive generations of the same sex were compared with successive 
generations of the opposite sex, that the sires of sires were older than the sires of dams, and that the dams of dams were older than the dams of sires, and that this relationship existed in the same way in the pedigrees of stallions, pedigrees of mares, and pedigrees of geldings. Also, that the distribution of race records corresponds to the distribution of ages-that is, the sires of sires were raced more than the sires of dams, and the dams of dams were raced more than the dams of sires. The explanation of this is found in the sexual character of energy acquired after puberty, and the capability of an offspring to transform such an inheritance into an ordinary character when that offspring is of the same sex as that of the parent which acquired the energ:. That this explanation is the true one is evident from the fact that a 2: 10 trotter is produced only when there is a combination of advantageous circumstances, and the general presence of this relationship shows it to be advantageous.

In Holstein-Friesian cattle there is no such 


\section{Holstein-Friesians}

relationship, and the reason is that milkproducing energy is not developed in one sex and later transferred to the other to be used there. Bulls do not develop milk-producing energy, and the bulls in our Holstein-Friesian pedigrees are generally young animals. The reason why the dams of sires in these pedigrees are older than the dams of dams is simply that the bulls give more opportunity for selection to eliminate young dams. 


\section{CHAPTER IX}

\section{MAN}

Growth of Mental Power-Eminent Men-Natural Distribution of Births in Two Generations-Distribution of Births of Eminent Men-Two Generations in New England Families-Sons of Eminent Men-Types of Character-Military, Artistic, Practical, and Philosophic Men.

\section{MAN is the toughest animal that lives. \\ He ranges the earth from pole to pole,} navigates the air, and fights the shark in his own element. In the matter of endurance he undergoes strains in six-day races and in general dissipation which would quickly destroy any other animal. In the matter of intellectual power he is in a class by himself. In accumulating energy before reproduction, as measured by the degree of his activity and the length of time elapsing before reproducing, he exceeds all other animals. He is also the only aninal which voluntarily fostpones 
reproduction to a time considerably after the attainment of the power of reproducing.

With horses we investigated the manner in which energy gets into the muscles in a form to produce fast trotters; with dogs we investigated that combination of muscular and mental energy which goes to make the champion setter; with cows we investigated that cnergy in the secretory organs which is involved in the production of milk; with men we will investigate that form of energy which produces mental power and mental characteristics.

Famous men are usually men of great intellectual power, but fame does not always rest on intellect. The Siamese twins were fimous but not for their mental porver. The men used in this investigation are the famous men of the world, due notice being taken of whether the fame was for brains or something largely independent of brains. Also, the investigation will be directed to the type of intellect, whether military, artistic, practical, or philosophical. 
Given a person of fair natural intelligence and one who follows some business requiring him to think and think hard, as the law or engineering. At twenty he has a certain amount of mental power, due partly to his inheritance and partly to the extent to which he has exercised his brains. At thirty his mental power has considerably increased, that increase being due to the mental work he performed in the intervening ten years. At forty there has been a further increase of mental power, and this development of mental power continues up to some uncertain age which is different for different persons. This difference in the mental power at different ages is common knowledge and was recognized in the Constitution of the United States. A man cannot vote before the age of 21, cannot be a Representative in Congress before the age of 25 , cannot be a Senator before 30, or a President before 35. A man under forty years of age could get very few votes for the office of President of the United States. His work involves 


\section{Man}

discretion, and discretion requires mental power.

The names of the intellectually eminent men selected for investigation, and the details of their pedigrees as far as known, were given in Control of Heredity. Here we will give the general results with a few additional facts learned since 1902. These facts show generally that the men of great intellectual power were sons of old or comparatively old fathers, and that the grade of intellect, from the top to the bottom of the scale, was approximately proportional to the age of the father at the birth of the son. Of course it is not possible to grade these intellectual giants with respect to each other, still, by dividing them into fair-sized groups by the ages of their fathers, it could be distinctly seen that the groups represented a graduated scale. The intellectual grade of the children represented the intellectual grade of the parents at the time the children were conceived.

In the case of horses it was pointed out that we sometimes get a 2 : Io stallion from a 
comparatively young sire, provided there is back of that sire and the dam an accumulation of energy enough to more than compensate for any lack of accumulation by the son himself. In all of those cases in which information was obtainable this same characteristic was found in the pedigrees of the intellectual giants. The father was comparatively young in a number of cases, but the factor time for two generations was never small in anything really eminent. In many cases the mother of the eminent man was found to be the daughter of an old and mentally active man. If the quantity of mental work performed by the father before getting the son affects the mental status of that son, then he should also be affected in like manner by mental labor performed by the maternal grandfather before the mother was conceived. But such things do not appear in general tables showing the average ages of fathers. They can be reached only by detailed examinations of individual cases.

The average age at which people marry and 
produce their children varies in different parts of the world. It is highest where intelligence is highest, and lowest where intelligence is lowest. In New England during the seventeenth and eighteenth centuries, the average age at the birth of surviving children was about 33 years for fathers and 3 I years for mothers, One-half of all surviving children were born before their fathers were 32. These averages are about the same as the average for western Europe. The average age of the fathers of 354 great men was found to be approximately 40 years, or seven years over the normal age. Over 80 per cent. were born after their fathers were 32 . The average age of the fathers of ten especially great men from different countries and from different races, was found to be approximately 55 years. This list of ten men consists of Aristotle, Augustus, Bacon, Buddha, Confucius, Cuvier, Franklin, Humboldt, Ptolemy II, and Solomon. It probably would be difficult to make another list of ten men representing an equal amount of intellect as that possessed by the ten whose 
names are given. That the average age of the fathers of these men should be 55 years is impressive. To find "contrary cases," it would be necessary to find ten men of similar mental greatness who were sons of fathers averaging less than 25 years. None such ever existed.

Pedigrees of horses, dogs, and cows can be made complete for four or five generations, and we can examine in detail the differcnt animals in each pedigree for the purpose of secing in what way and to what extent energy mas concentrated or dissipated. Similar pedigrces of eminent men can rarely be written because the facts are far in the past and are not recorded. The best me can ordinarily do is to tabulate and examine the length of time occupied in tro generations in the male line, and the number of cases in which this can be done is quite limited. As a preliminary it is necessary to furnish a table showing the normal lengths of time from births of grandfathers to births of grandsons, and then malie a comparison with this table. 
The data for the following table was obtained from the genealogies of New England families.

Ases of $256+$ Grandfathers when Grandsons Were Born, and Numbers of Grandsons at Different Ages of Grandfathers.

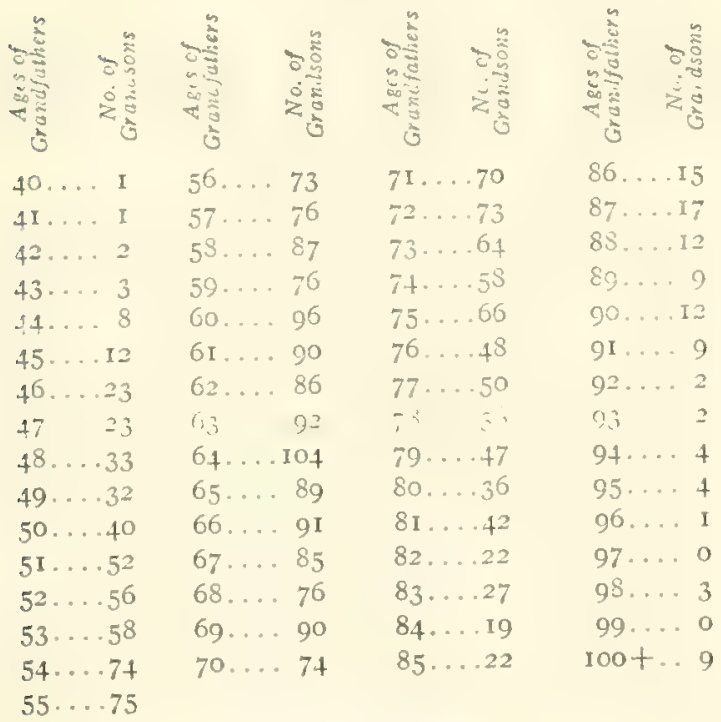

Average for 2 gencrations $\frac{1.47 .330}{26 n+1}=65.26$ years.

Dividing the whole number into four 


\section{I64 Dymamic Evolution}

approximately equal sroups, we have the following:

Grandfathers less than $58 \ldots$ 643 grandsons 58 to 64 , inclusive.......... . $\quad .635$ grandsons 65 to 72 , inclusive

Grandfathers 73 and over... 648 grandsons .638 grandsons

Taking the extremes we have:

Grandfathers less than $46 \ldots$ 27 grandsons

Grandfathers 92 and over... 25 grandsons

Tears Elapsing betTteg: Birth of Grandfather and Birth of EMinent Grandson

\begin{tabular}{|c|c|c|c|}
\hline & .122 & & \\
\hline adubon. . & $.115^{*}$ & Coligny, G. (1584) & 284 \\
\hline arpzov, J. B. $(172 \mathrm{C}$ & .113 & Bernouilli, John, 2d. & $.112^{*}$ \\
\hline & $.110^{*}$ & Franklin. & 108 \\
\hline & .107 & & \\
\hline & $.105^{*}$ & & 104 \\
\hline & .103 & illi, I & $102^{*}$ \\
\hline & $100^{*}$ & & $9^{9}$ \\
\hline A. B. & 97 & & 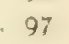 \\
\hline & 96 & Bur & $95^{\circ}$ \\
\hline to & 95 & & \\
\hline harles. . & 94 & & \\
\hline & 93 & 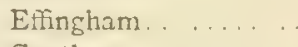 & \\
\hline illiers & 93 & Got & \\
\hline ope & 92 & & \\
\hline mine & 92 & & \\
\hline & 91 & & $0^{*}$ \\
\hline & $8 c$ & & \\
\hline Jana, R. H. & 87 & aw, Edward, Jr & r. \\
\hline
\end{tabular}


Naumann.......... $87 \quad$ Bach, J. C. F....... 87

Lee, R. H........ 86 Hcrschell, John..... 8 85*

Wharton......... 85 Carnot, C. M..... 87

Carnot, Sadi....... 84 84 Coligny, G. (1615)... 84

Canning, S........ 83 Lessing.......... 83

Carnot, L. N. M.... 8z Carnot, L. H...... 8z

Carpzov, S. B..... 82 Adıms, John...... 8 8 ז

Parker, T......... 8I Dana, F........ 8 80

Mann.......... 80 Mendelssohn...... 80

Helvetius... . . . . in Schiller.... .... . 79

Clinton, DeWitt.... 79 Wellington........ 79

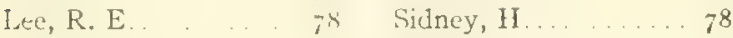

Darwin........... 78 Erskine..........78

Gladstone.........77 77 Livingstone, E....76 76

Story, W. W...... 76 76 Lowell........... 76

Lincoln.......... 76 Adams, J. Q...... 75

Arnauld.......... $75^{*} \quad$ Vernet, J. E. H..... 75

Hawthorne....... 75 Grant.......... 74

Huber........... 73 Cockburn......... 73

* Estimated.

By the addition of some forty or fifty names of men of more or less eminence this list might be continued down to a lapse of 58 years between the grandfather and the eminent grandson, at which point it appears to stop. I have never been able to find but one man of considerable eminenre who was born less than $j^{8}$ years after his paternal grandfather, and that one person is Jonathan Edwards. In tiis case we find old parentage 
on both sides of the house immediately bick of the grandparents. We also find here college education when college education was rare.

By comparing this list of eminent men with the group-tables just preceding it, it will be seen that all of these nien cume in the last group, representing less than 25 lur cent. of all births, and that thirty-one of then corre in that extreme which represents only one per cent. of persons born. An effort to find other men of similar mental caliber to fill up the shorter spaces of time between grandfather and grandson is futile. such mien never existed. We are therefore drircn to the conclusion that time between generations is a factor in the production of merital powcr. As mental power is energy, and time is a factor in the mensurement of cners; , there is no difficulty in understanding the rclationship of the two to each other. As nearly as may be, with the other factors unknomn, the mental energy found is proportional to the length of time occupied in concentrating it. 


\section{Man}

The effect of the length of time in two generations on mental ability may be looked at in another way. Take the genealogy of any New England family and select from it an early settler who had several sons, and whose sons had fair-sized families. This will give from six or eight to twenty or thirty grandsons whose births are distributed over from ten to forty jears. Arrange these grandsons in the order of their births and look in the records to see which ones became more or less prominent in their neighborhood. By taking a number of early settlers and thus obtaining and combining a number of groups of grandsons, it will be found that the later-born ones are the more prominent. An exception occurs when the earlicr-born grandsons and their fathers were college-bred men and the later branches were not. Also, exceptions cccur when the elder sons marry daughters of old men, while the younger sons marry daughters of young men. Even with these exceptions, the later-boril grandsons have the advantage. What follows was the result of taling 
$4^{8}$ such groups containing 506 male-line grandsons.

Of $4^{8}$ first-born grandsons........6 were prominent Of 48 last-born grandsons........20 were prominent

Taking them by threes, at the beginning and end of each group, the following was found:

Of first 144 grandsons born. . . . . . . .30 were prominent Of last $1+4$ grandsons born . . . . . .6.6I nere prominent

Further investigation showed that the carlier-born grandsons had the advantage of the later ones in college education. It was the practice in New England at that time to select the eldest son for a college cducation when it was practicable for only one in the family to have it.

In the study of genius it has been noticerl frequently that intellectual ability has riset gradually through several generations until it culminated in some great man, and then dropped suddenly to mediocrity. A few of these cases were investigrated, as far as records gave information, and each case indicated 
that mental ability in man rose in the same way that trotting ability rose in trotters,-by the performance of corresponding worl: before reproduction. Union with inferior mental development doubtless caused much of the decline in the sons of these great men, but that is only a partial explanation. A more complete explanation may be found in the fact that these great men, when they had sons at all, had them in early life and not in late life. The following men, sons of old men, hecame fathers only when young: Artwright, Bulwer-Lytton, Coleridge, Cromwell, Franklin, Jay, Peter the Great, Solomon.

The decline of mental ability and moral characteristics coming from early reproduction is well shown in the case of the "Jukes," investigated by Dugdale. This is a family famous for the production of criminals, paupers, and prostitutes. An analysis of the generations given shows that the lowest grade of intelligence and criminality cams: from the most rapidly moving generations, and that several branches of respectable citizens carce 
from the more slowly moving generations. There are more recent investigations by others of degenerate families, but, unfortunately, the published reports do not give information in regard to either of the factors of energy, or the directions in which energy was expended.

It is evident from the preceaing examination that muscular strength and mental strength stand on the same basis. Each is a special form of the same energy we know in the inorganic world, and each may be increased in amount by using it to do work. By an increasing amount of mental work, performed generation after generation, the mental power of human beings may be raised by successive stages to an indefinite extent. The same examination also shows us that if we decrease the amount of mental work performed between generations, each such decrease will result in a step domnward in intelligence, and that several steps in succession produce criminals, paupers, and prostitutes. 
As a general proposition, the man between twenty and thirty is aggressive, ambitious and conceited. He would rule the world with a club. This stage gradually merges into another so that as a general proposition the man between thirty and forty is in the artistic stage of life. He is a lover of poetry, music, painting, and sculpture. The artistic stage gradually merges into the practical stage which may be generally defined as between forty and fifty. The practical man looks at the dollars and cents, wishes to improve government, and has the qualities of statesmanship. As he passes beyond fifty into his older age he becomes philosophic in his sentiments and moral in his maxims.

These different qualities are simply different forms of one and the same mental energy within the man, and they are spread out through his life very much as red rays, yellow rays, blue rays, and violet rays, all from the same white light, are spread out by the spectroscope. Now let us make an assumption that the mental characteristics 
which are dominant in the father at different periods in life influence the mental characteristics of the sons conceived at those periods, and see what an investigation will show us. Militarism and 1ggressineness. Ant, Music and Literainere. Fathers less than 31 . Fathers 31 to 40.

Alexander

Bonaparte

Charlemagne

Charles XII

Frederick

Grant

Hannibal

Hastings

Pompey

Roosevelt

Bach

Beethoven

Mendelssohn

Goethe

Schiller

Shakespear:

Angelo

Raphael

Rembrandt

Saxe

Carlyle

Goldsmith

Scipio

Macaulay

Slulesmen.

Fathers 4 II 3050.

Bismarck

Canning

Carnot

Cato

Chateaubriand

Cromwell

Gladstone

Gracchus

Gustavus Adolphus

Macchiavelli

Peter the Great

Webster
Morality and Philosophy. Fathers over $5 I$.

Aristotle Arzauld Bacon Boyle Buddha Confucius Franklin Hall Leibnitz Moses Seneca Solomon 


\section{Man}

These groups represent distinct types of mental character irrespective of the station in life of the men within them. The persistence of these types to certain ages of father is very great as against the forces of environment. While men born in one of these divisions may show the type of chatacter represented in the next adjacent division above or below, the extremes do not meet. No mildmannered moralist of the type represented by Buddha and Confucius is found in the son of a man less than 3 I years of age, and ro aggressive military commander of the type of Alexander and Napoleon is found in the son of a man more than 5 I years of age. Natural military commanders may appsar in the moralist camp, and natural moralists may appear in the military camp, but the type of character shows through. Thus, Mohammed, whose father was 25 , would rule the world by the sword, and General Robert E. Lee, whosr father was 5I, went to wor because his moral obligations forced him to do so and not because he wanted to. 
Of the 354 great men, the ages of whose fathers were determined, it mas possible to classify 236 in one or the other of these groups in accordance with what history stated as their principal achievements. The result of that classification is given in the following table.

Mcntal Aptitudes of $236 \mathrm{Grea}$ : Men.

Ages of Falhers.

Under $3 I \quad 3 I-40 \quad 4 I-50 \quad 5 I+$ Total

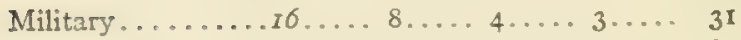

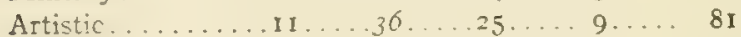

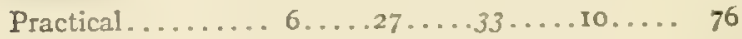

Philosophic...... $5 \ldots 7 \ldots \ldots$ I $\ldots .21 \ldots .48$

Totals........38 $\ldots 78 \ldots 77 \ldots 43 \ldots 236$ 


\section{CHAPTER X}

\section{LONGEVITY}

Cell Division at Different Ages-Effect on Offspring Produced at Different Ages uf Parents-GenealogiesLongerity of Different Offspring from the Same Parents-Infant Mortality-Immunity-Fecundity -Evolution.

THE doctrine of evolution assumes that reason of descent from some common ancestor. Of these relatives some normally live only a few days, some a few weeks, others a few months, still others a few years, and some live nearly a century. These are natural periods of life and the animals of each species reproduce their kind before death.

How did these striking differences in longevity come into existence? It will probably be said that they came about through fortunate variations. Quite true, but thcre 
is a cause back of those variations, and a statement that they are fortunate variations implies that some fortunate circumstances set that cause into operation. What is that cause? Or, if we do not know the cause, what set the cause into operation?

An animal body is composed of working cells and breeding cells, the working cells being derived from the breeding cells by differentiation. When two germ cells unite to form the first breeding cell, that cell multiplies rapidly by segmentation, accompanied by the growth of the individual cells to a normal size after each division. As morking cells berin to form by the differentiation of part of the breeding cells, the rate of cell division declines and the percentage rate of growth of the new animal becomes less rapid. This decline in the rate of growth coming from the decline in the rate of cell division is beautifully illustrated by Minot in Age, Growth, and Death. Thus, according to Minot's tables, the cell divisions on a child from birth to one year of age are frequent 


\section{Longevity}

enough to cause it to increase about 200 per cent. in weight during that time, but the decline in the rate of cell division is such that during the second year he increases only about 20 per cent. in weight, during the fourth year it is about Io per cent., and by the time he is twenty years old the rate of increase is reduced to about 2 per cent.

This decline in the rate of cell division is not the same for any two individuals, and differs widely for different kinds of animals, but in all cases in which the animal lives to become adult there comes a time when the rate of cell division just balances the wastage, and growth in weight ceases. Still later there comes a time when the rate of cell division will no longer compensate for cell wastage, and the arimal shrinks in size and weight.

It has been determined that, generally speaking, cells are of comparatively uniform size, and that the difference between a large animal and a small animal is a difference in the number of cells and not a difference in their size. The different animals of any kind, 
as men for example, are born to grow to approximatuly equal size, and, consequently to hate an approximately tqual number of cells in their budies. From these facts it appears that a definite number of possible divisions is the heritage of cach animal, and that when this number of dirisions is exhausted the animal dies. This failure does not occur at all places at once as it did in Holmes's One Horse Slialy, but occurs sometimes in one place and sometimes in another, and whenever it cceurs in a vital organ, dcath follows. For the purpose of our aremment we may say that death occurs from old aรe when the possible number of cell divisions is nearly exhausted.

Without attempting to justify the for going hypothesis in regarl to the possible rumber of cell divisions, wc may say that, if it is approximatcly correct, there are tmo mays in which longerity ma be increased.

First, ly increasing the possible number of coll divisions; and

seound, ?y choclsing the rate at rhich cell 


\section{Longevity}

divisions occur so that the number involved in the animal's heritage will linst for a longer time.

IVt have seen before, when considering the mental aptitudes of men, that the distribution of energy as it exists in parents at the time of reproduction controls, in a measure, the distribution of energy in the offspring. Thus, the man whose dominant mental characteristic is ambition is the son of a man in the ambitious stage of lift, the natural artist is the son of a man in the artistic stage of life, the practical man is the son of a father in the practical stage of life, and the philosopher comes from a father in the philosophic stage.

If the distribution of mental energy in the parent controls the distribution of mental c1ncrsy in the offspring, then the distribution of coll energy in the parent should similarly control the distribution of cell cnergy in the offspring. Construed, this means that if reproduction occurs when cell division is rapid in the parent, then rapid cell division will be dominant in the offspring: while if $r$ production occurs after the rate of cell 
division has been reduced in the parent, the result should check the rate of cell division in the offspring. As the rate of cell division becomes gradually less and less as the individual grows older, this means that, within limits, the older the parents are at the time of reproduction the greater should be the longevity of the offspring.

The investigation which follows ras made for the purpose of testing the accuracy of this deduction as applied to human beings, and the records used were the genealogies of early New England Families. These genealogies, are human herd books in which are recorded the dates of births, marriages, and deaths of all individuals in certain groups for several generations. A primary consideration in using these books for this purpose is the selection of proper material. Obviously, the best material is that which represents the relative longevity of brothers and sisters, and the larger the families in which we find these brothers and sisters the better is the material. At this point it is proper to mention that 


\section{Longevity}

there is a second deduction from general principles and the known habits of human beings, the conclusion of which is that the older the parents the greater is the percentage of infant mortality. The "infant mortality" used in this investigation was all deaths occurring between birth and twentyfive years of age, and the brothers and sisters compared for longevity were those which died after arriving at twenty-five. Only those families were used which had four or more adults living long enough to be included in the table. The average number per family was about six.

In preparing the table a sheet of paper was used having vertical columns, and at the heads of the columns were placed the numbers "21," "22," "23," ctc., representing the ages of the fathers at the births of the children recorded in the columns below. If a family had one child when the father was 25 and living to the age of 60 , a second child when the father was 27 and living to the age of 65 , a third child when the father was 30 
and living to the age of 5.5 , and so on, then the numbers " 60, ," "65," and " 55 " were placed in the columns headed " 25, , " 27, , and "30," respectively. The arerage was then found for each columm. These arcrages reiresented the expectancy of life at the agre of twenty-five for brothers and sisters in families of four or more. The total number of individuals was 1105 , orisinally placed in five tables of approximately the same size and afterwards conihined into one table. With minor variations, each of the five tablos showed the same general result. The full table is as follows:

Expectancy of Life at Agt 25 for 1105 Persons. and Rilutionslip of Age of Father at Birth of Child.

\begin{tabular}{|c|c|c|}
\hline Ages of Fathers & $\begin{array}{l}\text { Yumh-r of } \\
\text { Pirsons }\end{array}$ & $\begin{array}{c}\text { Aacrame age } \\
\text { Death }\end{array}$ \\
\hline Under 25. & $\ldots 8_{3} \ldots$ & .62 .63 years \\
\hline 25 to 29 . & 233. & .65 .20 years \\
\hline 30 to 34 . & 266. & .65 .28 years \\
\hline 35 to 39 . & $199 .$. & $.65 .4 \mathrm{I}$ years \\
\hline 40 to 44. & 165. & .68 .02 years \\
\hline 45 to 49 . & $88 .$. & .66 .28 years \\
\hline 50 and over & $71 \ldots$ & .70 .27 years \\
\hline & 1105 & .89 yea \\
\hline
\end{tabular}


The diagram for illustrating this table shows that the longevity of children increasis as the age of the father increases up to the age of 29 for the father, that it then remains practically stationary for all surriving children born during the next ten Jears, and that from that date it increases rapidly as the age of the father increases. Taling the entire diasram it may be said that wh four years added to the ase of the father adds apyrn:imately one year to the natural longevity of the child.

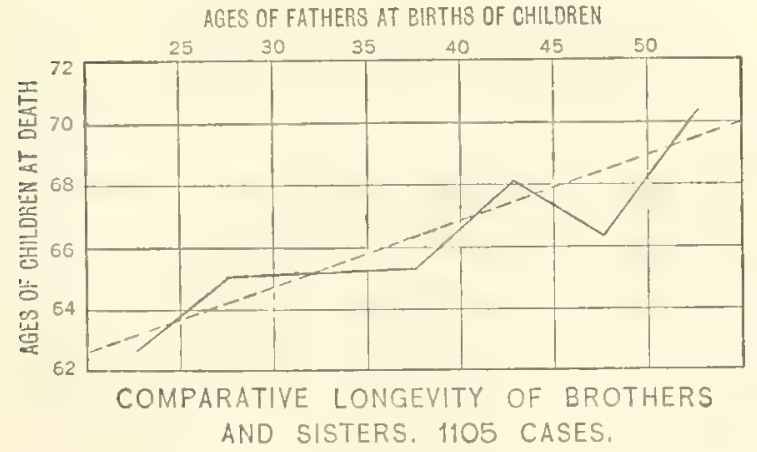

The effect of the age of the father on the normal longevity may le lool:ed at in another 
way. Of the 582 persons born when their fathers were 34 or less years of age, 27 , or 4.65 per cent., lived to the age of 90 ; while of the 523 born after their fathers were 35 years of age, 32, or 6.12 per cent., lived to the age of 9o. Also, taking the 83 born before their fathers were 25 , and the 71 born after their fathers were 50 , we have:

\section{Living at 80}

Livirg at 90

Fathers less than $25 \ldots \ldots 12 \ldots \ldots \ldots$. . . . None

Fathers over $50 \ldots \ldots \ldots .46 \ldots \ldots \ldots .4$

The distribution of infant mortality was not investigated extensively, but the I I 3 cases found are sufficiently numerous to shor that the ratio of infant deaths to total births increases uniformly as the parents grow older.

\begin{tabular}{|c|c|c|c|c|}
\hline $\begin{array}{l}\text { Ages of } \\
\text { Fathers }\end{array}$ & $\begin{array}{l}\text { Infant } \\
\text { Deaths }\end{array}$ & $\begin{array}{l}\text { Percent- } \\
\text { age of } \\
\text { Deaths }\end{array}$ & $\begin{array}{c}\text { Percentage } \\
\text { of Births }\end{array}$ & .Y. \\
\hline Under 26. & II.... & 9.734 . & . 12.890 & .. 75.525 \\
\hline 26 to $30 \ldots$ & $23 \ldots$ & 20.354 & . 25.056 & . 81.234 \\
\hline 3I to $35 \ldots$ & . $23 \ldots$. & 20.354 & .. 24.719 & . 82.341 \\
\hline 36 to $40 \ldots$ & . $20 \ldots$ & 17.800 & . 18.056 & . 98.026 \\
\hline 41 to $45 \ldots$ & . $19 \ldots$ & 16.710 & $\ldots 11.777$ & . 142.759 \\
\hline 46 and over. & $.17 \ldots$ & 15.0 .48 & ․ 7.502 & .200 .600 \\
\hline & 113 & 100.000 & 100.000 & \\
\hline
\end{tabular}


The third column reduces the actual death: to percentages, and the fourth rolumn gives the normal percentages of births at the corresponding ages of fathers. The last column gives quotients arising from dividing the percentages in the third column by those in the fourth column, and represents the relativs infant mortality at different ages of fathers. Thus, if in a given community, the total infant mortality were 20 per cent. of the total births, those occurring among the children of fathers less than 26 would be only 75.5 per cent. of this 20 per cent., or 16 per cent. in all; while those occurring among the children of fathers over 46 would be 200 per cent. of the 20 per cent., or 40 per cent. in all. Or, stated in another way, the relative deaths among the children of the older parents are nearly three times as numerous as among those of the younger parents. Taking the tables for longevity and for infant mortality together, it will be seen that the children of young parents are more likely to survive to maturity than the children of old parents, but of 
those which do survive, the children of old parents live longer than those of young parents.

Infant dcath occurred most frequently to the last child of the family, and indicated failing health of the parents. When an infant death occurred in the middle of a large family it was noted that with great frequency the nearest child, before or after the infant death, lived a luss length of time than the other children. These facts indicate periods of ill health on the part of the mothers at about the times of the infant deaths. We may, therefore, revise the former statement and say that as long as parents retain their health and rigor, the older they are the greater will be the natural longevity of their children.

A partial, but no systematic inrestigation was made into the etfects of several successive generatiun: of lit" reproduction on longevity, with indicution. that the effects are cumulative in the sante wy that mental and physical energy is cumulative. Thus, several famili... were found which had four or five 


\section{Longevity}

members living to over eishty years of age. When these were traced lack they were found to have come from three or fuur generations of late reproducing stock. Me'n of great intellectual ability also usually live longer than ordinary jeople, and it has been previously shown that they are from successive generations of old parents.

There is another reason why late reproduction is conducive to longevity by preventing early death, and this is immunity. A person who is attacked by disease and overcomes it is more or less immune to subsequent attacts of the same kind, and the older he is the more likely he is to have acquired this immunity. Resistance to disease involves the expenditure of energy, and it has been shown before that the expenditure of energy through organs causes a concentration of energy in the organs through which the expenditure occurred. Also, that a similar concentration appears in offspring produced after the original concentration occurred. From this it would appear that immunity may be inheri- 
ted from parents who have acquired it, and that by continual vaccination the race may become immune to small-pox. By repeated small duses Ehrlich produced a race of try. panosumes which were immune to trypan red, and this resistance was transmitted through many generations.

Germ cells begin to multiply by segmentation at the time of puberty, and the rate at which they multiply corresponds more or less to the rate at which the ordinary body cells multiply. They increase very rapidly soon after puberty, but the rate of increase sradually declines and finally ceases in very old persons. We see the result of this in the fact that animals are more prolific when young than when old. In man we see this in the fact that the greatest number of children are born when their fathers are 30 years of age, and this in spite of the fact that some men do not marry until after that age.

From what has been stated hefore, the natural deduction from these facts is that fecundity should te greater in the offspring 


\section{Longevity}

of young parents than in the offspring of old parents. This was inrestigated in human beings with the following results:

Fecundity of Offspring Infucnced by Age of Parents roo sons of young fathers had........568 children roo sons of old fathers had........... 309 children

The "young fathers" were those 30 or less, while the "old fathers" were those 40 or more. While a difference is to be expected, the size of the difference is surprising. If the tabulation were extended to 1000 instear of 100 families, the percentage of difference would probably be less. There is, however, much difficulty in finding large numbers of heads of families who were sons of men over to years of age. More than one thousanrl families were investigated to find the onc hundred whose heads were sons of men over forty.

The production of germ cells appears to be a compound of rate of cell division and function performed, - a conjoint action between breeding and working cells. The rate of cell 
division is greatest at the beginning of life and the greatest functional caracity is near the end of life. A compound of the tro should be maximum at some point betreen the tro. As applied to germ cells, the maximum of fecundity should be, not at the beginning of the production of germ cells, but some little time later. Thus, in the case of hens, the maximum of fecundity, as indicated by number of eggs produced in a given time, appears some months after she begins to lay. We have seen before that the functional characteristics dominant in the ofispring are those which rere dominant in the parent at the time the offspring mas conceived. Hence, to increase laying capacity, eggs for hatching should be taken which are produced by hens when they are in their period of greatest fecundity.

In the process of evolution from slort life to long life it is necessary that the fertile period be extended at the same time that life is extended, otherwise there would be a limit to extending life hy later reprorluction. That 
the fertile period has been extended to later ages in correspondence with the extension of life we know by observing aninals which live different lengths of time. The longer is the nurmal life of the animals of any given species, the later does the fertile period begin. We may find an explanation of this in the same thing which explains increasing longevity. If late reproduction tends to checl: the rate of ccll division, so that the total number of cell divisions in:olved in ordinary life are extended over a greater length of time, then that checling of the rate of coll divisions will cause a longer time to clapse before the young animal has arrived at that stage of development which will permit it to produce germ cells. Briefly, that thing or action which lengthens life lengthens all portions of it, very much as all portions of a rubber band are lengthened when the band is stretched.

Here we have set before us the process of evolution from a lower to a higher stage. If 
a generation reproduces a little later than previous generations, then that part of the next generation which survives to reproduce will live a little longer than the present generation and at the same time will have its reproductive period extended. If the next generation utilizes its additional time to reproduce still later, then the third generation will live still longer and have its reproductive period come still later. If the successive generations are lethargic, then we have increased length of life without noticeable increase in mental energy, as in the tortoises. If the successive generations are active, then that activity concentrates energy in proportion to the degree of activity and the length of time employed, and we have steadily increasing mental power, as in man.

Limit? There is no known limit nor are there present indications of one. Man lives much longer than many mammals to which he is said to be a distant blood relative, and during the past his length of life has been gradually extended. The same processes 
which extended his life in the past are in operation to-day, and a knowledge of what they are and how they operate will enable him to utilize them as he will.

13 


\section{APPENDIX}

FROM the dynamic standpoint the pedigree of Hambletonian is one of the most remarkable in existence. A mere reference to the figures representing ages of sires and dams mill show that the factor time is abnormally large for each animal in each generation as far as those animals are knomn. It is doubtful if any other horse ever produced was the product of such extreme ages as those in this case. The amount of work per unit of time done by these animals is also great.

Messenger was the sire of Mambrino, Bishop's Hambletonian, and Silvertail. He was a thoroughbred which had been raced when young and subsequently had traveled about the country a sreat deal. He was fairly popular in middle life, but at the time he got the animals in this pedigree his stud fees had been reduced from $\$ 35.00$ to $\$ 15.00$, and he had been sent to the country to be bred to farm mares.

Mambrino was raced as a four-year-old and subsequently changed hands many times at a value of alout $\$ 200.00$ to $\$ 300.00$. At the same time other :stallions were valued at from $\$ 3000.00$ 


\section{Appendix}

to $\$ 5000.00$. He was used under the saddle and not in harness. Abdallah could trot under the saddle in about $2: 50$, which was considered fast at that time, but he was not popular with breeders. At about the time he got Hambletonian, or soon after, he was sold for five dollars. Belfounder is said to have been able to trot a mile in about three minutes. It is said that old Belfounder was a trotter in England, but his history is unknown. Bishop's Hambletonian belonged to a man who was fond of driving ahead of every one else on the road, and he used his horse for this purpose.

The Kent Mare was a road mare put to breeding after being crippled in a runaway. The other animals in the female line, including the dam of Silvertail, were used, from about I 790 to 1830 , by a drover who traveled about New York State collecting cattle and taking them to market in New York and Albany. He did not hesitate to force his mares to travel 100 miles in one day. Velocity was a trotting race mare in England. Amazonia was a coarse, "rat-tailed" road mare, said to have got a record of $2: 54$ in I 820 .

Several of the 2 : Io trotters are by sons of Hambletonian. In those cases the pedigrees for five generations go back to the birth of Messenger in 1780 and include what is given in the pedigree of Hambletonian. 


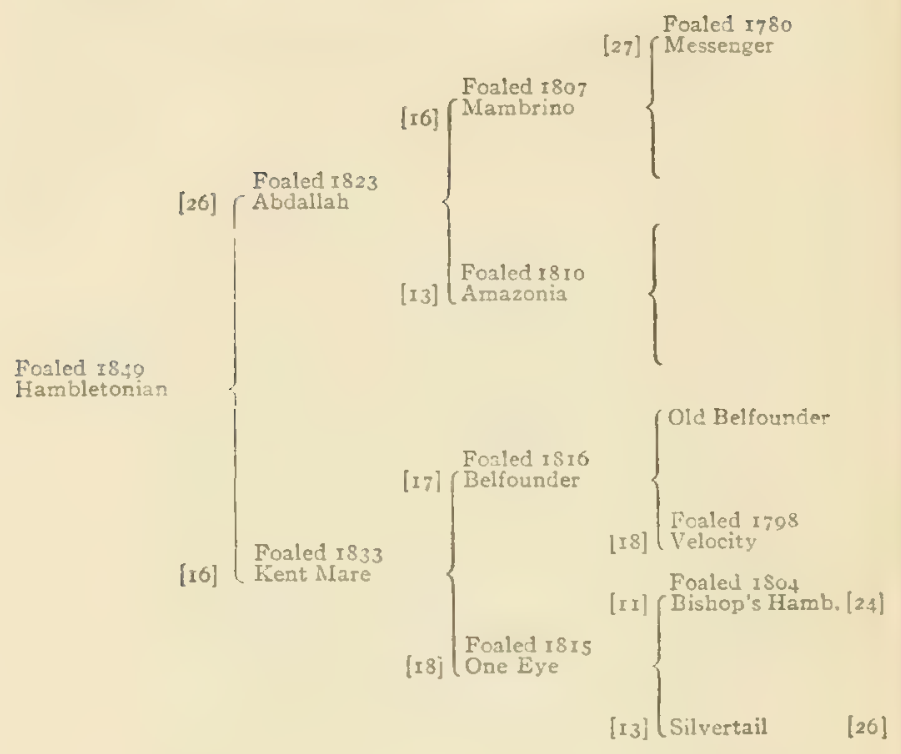

\section{PEDIGREE OF HAMBLETONIAN 10}

The figures in brackits represent time betreen generations and are known as "hirth ranks." Thus, [26] is Hamblunian's birth-rank, and "Hambletonian [26]" in licaic: that Hambletonian was the son of a sire 26 years of age.

In 1 ist I. II. Mallace issued a "Trotting Supplement" to his stud Bonk, and in I87 I was pulblished the first resular volume of the Ameriran Trotling Resister. In IS, Association of Trottins Irirse Brecders mas or- 


\section{Appendix}

ganized and took supervisory control over the Trotting Register. Since 1891 the Register and the Year Book have been owned and published by the American Trotting Register Association. It is the object of this Association to keep full and complete record of all animals belonging to the trotting breed, and to that end the volumes published by it are huge affairs.

In I907 "Algernon" published a list showing that 32 of our I80 2 : Io trotters were nonstandard, and added the statement that there were "quite a number" more of the same kind. It appears that many of them were nonstandard when bred but became standard under the rules because their dams each produced one other animal capable of trotting in $2: 30$. According to Busbey, this non-standard list of 2 : Io trotters had grown to 88 at the end of 19II. He says: "At the head of the barred list is the champion trotter Uhlan, I : $583 / 4$, a horse of commanding appearance and faultless action."

What would be thought of cattle breeding if champion Holsteins, champion Jerseys, and champion Guernseys were bred in ways which did not permit them to be registered? What kind of breeding operations would it be if the breeders did not breed their champion Southdowns, champion Berkshires, and champion Plymouth Rocks within the breeds and did not 
know from what progenitors these champions were produced? The statement that improvement comes through selection does not have quite the same meaning for trotters that it has for other animals. With trotters it almost invariably means the selection of the blood of a horse which is dead and which was considered of little value for breeding purposes when alive.

An industrious statistician traced all of the standard trotters to their tail-male ancestors born before $I S 50$, and found that they came from one or another of no more than seventeen horses having different origins. Condensed, his table is as follows:

\section{All Trotters Descended in Tail-Male from}

Hambletonian............... I5,450 trotters

Mambrino Chief. ............... I,045 trotters

Justin Morgan............... 975 trotters

Andrew Jackson (Clay family)....... 840 trotters

Miscellaneous (13 horses)......... 687 trotters

Unknown................ 3,241 trotters

Trotters at end of $1906 \ldots \ldots \ldots .22,238$ trotters

A similar tabulation for the 2: 10 trotters involved in our investigation yields the following result: 


\section{Appendix}

$2: 10$ Trotters in Tail-Male from

Hambletonian. . . . . . . . . . . . . . I 57

Mambrino Chief...................... I3

Miscellaneous ( 7 horses) . . . . . . . . . . Io

$2: 10$ Trotters................. 80

At the same period before 1850 there were many thousands of other stallions which were used for breeding purposes and were closely related to these horses. The fact that these other horses have disappeared, as far as the male line of descent is concerned, shows the extent to which breeding operations have eliminated those horses incapable of transmitting energy to their descendants. That the same process of elimination has continued since that time is evident from the fact that the successful lines of descent from these horses is through only a very small proportion of their sons. The process by which this elimination has been brought about in horse breeding can best be described by taking arbitrary numbers for an illustration and then explaining the successive steps in the process.

Let us assume the early part of the nineteenth century when there were some hundreds of thousands of horses in the country. These horses will be considered as the first generation and be designated as "Gen. A." The breeders select from these horses Iooo stallions to become 
sires of Gen. B. These stallions are sons of horses of all ages, but the average of all their sires is about ten years, that being the normal average for the breed.

These 1000 stallions in Gen. A. have about 100,000 sons in Gen. B. As the result of tests, principally on mares and geldings of generations $A$ and $B$, the breeders select 1100 horses from Gen. B. to become sires of Gen. C. These selected horses in Gen. B. are sons of sires averaging ten years of age, but they do not come in equal distribution from the 1000 horses selected in Gen. A, that is, they are not one son from each sire and an extra son from each of a part of them. On the contrary, by tests, the breeders decide that certain blood-lines are superior to others, and, as a result, the IIoo selected in Gen. B probably come from no more than 400 of the Iooo originally selected in Gen. A. When the breeders selected the horses in Gen. B. they eliminated about 600 horses from their original selection in Gen. A, and when we examine the four hundred which remain we find them to be sons of horses averaging about thirteen years of age. It is evident that the horses eliminated because unable to transmit as much energy as others were principally the sons of young sires.

The I Ioo selected horses in Gen. B probably have 120,000 sons in Gen. C, out of which the breeders select about $\mathbf{I} 200$ to become sires of 


\section{Appendix}

Gen. D. These selected horses in their turn are sons of sires areraging abuut ten years of age, but they come from only about 450 of the original I Ioo selected in Gen. B. When we examine the remaining 450 in Gen. B. We find that they were sons of horses in Gen. A which averaged aluout thirteen years of age at the time these particular sons were born. The brecler's, in sclecting from Gen. C, eliminated from Gon. B. principally horses which were sons of young sires in Gen. A. Cutting down the lines of descent in Gen. B from I Ioo to 450 made a further elinination in Gen. A, so that when the selection is made in Gen. C descent runs back in male line to not more than about two hundred horses in Gen. A. When we examine this remaining two hundred in Gen. A we find that they are sons of horses averaging about fourteen years of ase, which means that there has been a further elimination of sons of young sires in Gen. A.

When the breeders select from Gen. D those horses which they intend to use to produce Gen. E, they take sons of horses averaging about ten years of age, but in doing so they climinate part of their previous selection in Gen. C, which in turn eliminates more from Gen. B, and this in its turn eliminates more from Gen. A. Each one of these eliminations bears more heavily on the sons of youne sires than it does on the sons of old sires, the result of which is secn in the fact that 
the farther we go back in horse pedigrees the older the sires appear.

This elimination coming from selecting for energy by blood-lines is not confined to the sons of young sires. The sons of old horses are also climinated in large numbers. A critical examination of those horses remaining after several successive selections shows that what was really first eliminated were the sons of those horses which did the least amount of work before being bred, and what was longest retained were the sons of those horses which did the greatest amount of work before they were bred. The age is simply the factor time in work performed, the other factor in important horses being obtainable from horse history.

Hambletonian was the product of sixty-nine years in three generations in the male line, and Mambrino Chief was the product of sixty-four years in the same gencrations. Hambletonian came from four known generations of old and hard-rorked female ancestors, while Mambrino Chief was out of an old road mare of unknown ancestry. Hambletonian was trained some when young and was driven regularly on the road during his mature life; Mambrino Chief was a failure in the stud in his youth, was taken from the stud and trained and raced, and was later a successful sire. The remarkable difference in the amount of energy found in the offspring of the 


\section{Appendix}

two periods in the life of Mambrino Chief has been ascribed to the "climatic out-cross." His earlier life was spent in the north where Hambletonian was, and his later life was spent in the south. In other similar cases the "climatic outcross" worked in the opposite direction,-early failure in the south and later success in the north.

Of the horses born before 1850 , none approaches Mambrino Chief in importance as the head of female branches. Either directly through his daughters, or mediately through his sons' daughters, he appears one or more times in nearly all of the $2: 10$ pedigrees. Next in importance stand Pilot Jr. and American Star. All other horses are of minor importance in comparison with these. The ages of the sires and dams of these horses are as follows:

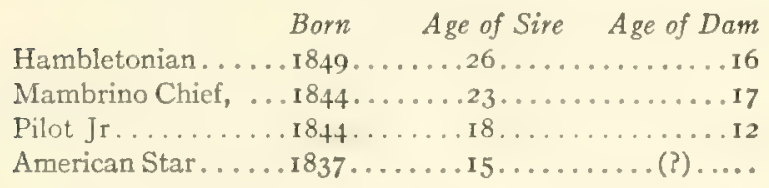

As these horses appear frequently in the second, third, and fourth generations back from our 2 : Io trotters, it is not difficult to see what it is that causes the high average age of the third, fourth, and fifth generations. As the breeders have been selecting continuously those 


\section{Dynamic Evolution}

blood-lines which gave evidence of the largest stores of energy, and have been discarding all others, it is easy to see why horses bred as these were are the principal things left after fifty years of elimination. 


\section{BIBLIOGRAPHY}

The principal contributions by the author on this subject are given below. The same periodicals during the same years contain many contributions by others and editorial comments giving additional information and representing all shades of opinions. The periodicals which have discussed this subject more than others are The Horseman, The Horse Review, The Horse World, and the American Horse Breeder.

Control of Heredity. Devoted principally to human beings; 343 pages. $\$ 2.00$, postpaid.

"The Origin of Speed." A disconnected series of articles, Dec. 2, 1902; Jan. I3, Feb. Io, June 30, Scpt. I5, Dec. 15, 1903; Jan. 19, March I, March 15, 1904. The Horseman, Chicago, Ill.

"Breeding the Trotter." A series of 23 articles from May 16 to Nov. 28, 1905. The Horseman.

"The Laws of Heredity." A series of six articles from March I to April 5, 1904. The Horse Review, Chicago.

"The Evolution of the Setter." A series of ten articles from Dec. 17, 1904, to May 20, 1905. The American Field, Chicago, Ill.

"The Dynamic Theory." A series of six articles from Jan. 20 to March 2, 1910. The Horse Review.

"Development of Holstein-Friesian Cattle." A series of five articles, April to June, 1907. The Holstein-Friesian Register, Brattleboro, Vermont. 


\section{Miscellaneous Contributions}

The Horseman, March 22, Dec. 13, 1904; Jan. 2, Feb. $6,1906$.

The Horse Review, Aug. II, I903; Jan. 26, I904; March I4, May 9, 1905.

The Horse World, Buffalo, N. Y., May 15, July 21, Iyo3; Jan. 30, Feb. 27, 1906; April 9, 1907.

The American Sportsman, Cleveland, Ohio, Feb. 26, April 2, April 23, May 21, I903.

The Western Horseman, Indianapolis, Ind., June 19 , July 17,1903 .

American Horse Breeder, Boston, Mass., March 31, May 5. June 16, 1903; Feb. 23, March 22, 190.4.

The American Naturalist, Lancaster, Pa., April, Sept., I9ro; Sept., IgIr.

Annual of American Breeders Association, Washington, D. C., vol, ii., p. 206. 


\section{INDEX}

Ability....................... $10,31,60,168$ Activity...............47,52,54, 103, 142, I 56 Adult stage.................... 38,91, I09, I 29 Advanced registry............... 143, 146, I47, I5I Age a factor of energy........29, 41, 82, 85, 103, I 41,158 Age, average for breed. ..........23, 85, I34, I5 I, I6I Ages, effect of different...103, 152, 158, 172, 179, I84, I86 Artificial product.................... 80, I28

Best age.................88, I03, I I 8, I 22

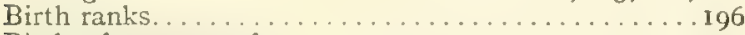

Births, frequency of . . . . . . . . . . . . . I 53 Blood.................22,63,70,73, 129, I32 Brain, energy of................... II, I56, I 70 Breeding methods............6.62, 66, 72, 130, I33 Breeders' prejudices.....................63 Brood mares...................53,61, 98, I I4 Brothers........................76, II3, I80 Bulls............................ I5I Butter fat...................... 145, 152

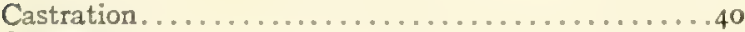

Causes........................ 71,176 Cell division.................... I76, I9I Characters, secondary sexual, $21,38,43,54,84,95,1$ ro, $129,136,154$

Characters at different ages. ..............42, I7 I Characters transformed.................44, 110

Champions....................96, I33, 141, 197

Conservation of energy.............. 12,25,27

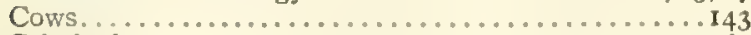

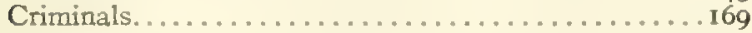

Dams..................... 52, 92,94,98, 110

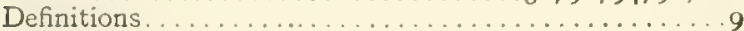

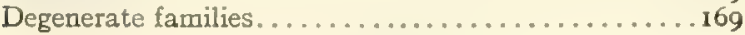


Diagrams........................ 55,183

Dogs ....................................

Dynamic condition.......................

Dynamic development. ....20, 48,49,86, 94, I03, II I, I42

Early speed...................... 124, 129

Elimination........ 50, 102, I35, I39, I49, I50, I55, 199

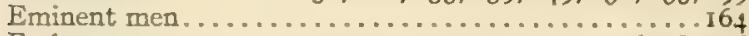

Endurance.....................46,48, 156

Energy ....................... 3, 7, 12

Energy, available...............9, 15, 17,23,46 Energy, concentration of, $13,18,27,29,46,81,106,144,158$ Energy, dissipation of ..........13,28,32,41,46, 107 Energy, factors of . . . . . . . . . . . $7,8,46,82,85,128$ Energy, forms of................14, 40, 170, 171

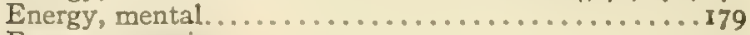
Energy, organic...................... II, I9 Energy, vehicle of ...................... Evolution........................... 191

Expectancy of life.................... 182

Experiment........................68, I24

Explanations.................25, 106, 110,154

Extraordinary animals..............27,33,70

Fecundity....................... 189, 190

Fertility of horses...............63, 76, 86, 89

First progeny..................99, 149, 152

Foals, number of................73,76, 112, 121

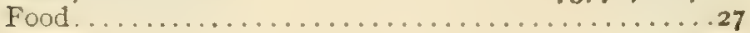

Force......................

Geldings....................40,89, 98, 108, II2 Generations..... 19, 32, 39, 56, 102, 106, 128, 140, 169, 200 George Wilkes................65,72, 100, 108, III Germ cells......................176, 188, 189 Gestation, period of................... 41, 153

Hambletonian...................64, 71, 196 Hambletonian, sons of . . . . . . . . . . . . . . . . . . . 65, 71

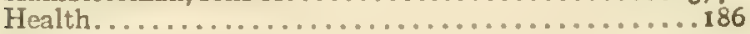

Hens............................... . . . . . . .

Heredity........................ 19, 2 I

Holstein-Friesians. . . . . . . . . . . . . . . . . I43

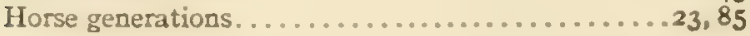


Horse history

64,123

.........23,58,79, 108

Idleness. . .28, 33, 44, 49, 52, 91, I06, I14, I1 7, II9, I30, 192 Immature stage............43,54,91, I00, I09, II I

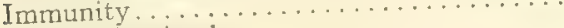
Imported anima!s. ............... I33, I40, 147

Inbreeding . . . . . . . . . . . . . . . .

Inertia...................... 81,184

Infant mortality........................ 34, 187

Inheritance..................... $31,41,44,50,51,81,138$

Jukes.

.169

Kindergarten

126,127

Law of nature ........ $5,21,26,50,86$

Lines of descent. . .80, 93, 109, I 19, 127, I34, 138, 152, I98

Lines of limitation

Longevity ................ 175, 183, I 86, I 87

Man

.156

Mares.

$89,94,1 \pm 4$

Matter

Maxim of breeders

$I, 6,1 I, 138$

Mental development ............... 158, 168, 192

Milk

Non-standard animals.

$.92,96,197$

Offspring at different times............ I 8, I49, I 82

Offspring registered...

Opinion of breeders.................65, 75, 90

Performers.............77, I I I, I I 3, I I 8, I 2 I, I 36, I 39

$\ldots \ldots \ldots \ldots \ldots . . . \ldots \ldots, 39$

Potential ..... $8,17,22,25,35,46,77$

Prejudices. ..........

Puberty

Raced and unraced horses. 65, 74,77,85, 95, I02, II 3, II 7 Race records. 
Reciprocal crosses..................... I37

Reproduction. ...................... I9

Resistance..................... I, 7, 21, 43, I 88

Road mares......................67, II6

Rule..........................

Selection..............69, 138, I5 I, 155, 198, 200

Setters. . . . . . . . . . . . . . . . . . . 3 I

Sex...................... 38, I 12, 136, 153

Sexual maturity....................38, 43,9 I

Show animals. ................... I35, I38

Sires..................5I, 83,86, 90, I I I, I I 4, I I 7

Special animals. ......87, 97, II 1, II 5, I I8, I2 +, 152, 202

Special men...................16r, I64, 169, I72

Speed.......................23, 24,60,80

Stallions..........51,62, 71, 76, 83,85,93, IOI, I I I

Sterility........................63,89

Structure........................ 2, 138

Stud and track.........6.63, 75, 90, 93, I0I, 103, I1 2

Tables, 85, 90, 92, 93, 94, 98, 102, I05, I06, I I3, I14, 163. $164,168,172,174,182,184,189,198,203$

Theory..................... 15, 57,63,8

Thermodynamics.................. I2, I3

Thought......................... II

Time................. $7,29,41,45,82,85,88$

Time between generations. . . . 23, 85, I33, I5I, I6I, I66

Training .............. $31,59,67,105,113,124,134$

Transmission. ................ 32, 38, 44, 95, 100

Trotters......................23,58, 139, 198

Trotters (2:10) ...............30, 34, 79, 106, 199

Trotting families, instability of . . . . . . . . . 70,74

Trotting records..............24, 48,60, 83, 91, 95

Trotting register..........64, 85, 92, 95, 114, 123, 197

Two generations... . . . . . 108, 117, 122, 128, 160, 163, 167

Types of character............... I57, 17 I, 174

Variability....................4, 5, 20, 43

Work......2, 10, 16, 44, 81, 85, 88, 103, 107, 146, 170

Young parents..........94, 134, 137, 160, 169, 189 






\section{PLEASE DO NOT REMOVE CARDS OR SLIPS FROM THIS POCKET}

\section{UNIVERSITY OF TORONTO LIBRARY}

QH

371

R35

Biological.

Medical
Redfield, Casper Lavater

Dynamic evolution 
